This document is confidential and is proprietary to the American Chemical Society and its authors. Do not copy or disclose without written permission. If you have received this item in error, notify the sender and delete all copies.

\title{
Biomimetic planar Polymer Membranes decorated with Enzymes as Functional Surfaces
}

\begin{tabular}{|r|l|}
\hline Journal: & Langmuir \\
\hline Manuscript ID & la-2018-00541g.R2 \\
\hline Manuscript Type: & Article \\
\hline Date Submitted by the Author: & 27-Jun-2018 \\
\hline Complete List of Authors: & $\begin{array}{l}\text { Draghici, Camelia; University of Basel, Chemistry Department } \\
\text { Mikhalevich, Viktoria; University of Basel, Department of Chemistry } \\
\text { Gunkel-Grabole, Gesine; University of Basel, Department of Chemistry } \\
\text { Kowal, Justyna; University of Basel, Department of Chemistry } \\
\text { Meier, Wolfgang; University of Basel, Department of Chemistry } \\
\text { Palivan, Cornelia; University of Basel, Chemistry Department }\end{array}$ \\
\hline
\end{tabular}

SCHOLARONE

Manuscripts 


\title{
Biomimetic planar Polymer Membranes decorated with Enzymes as Functional Surfaces
}

\author{
Camelia Draghici ${ }^{a, b}+$ Viktoria Mikhalevich ${ }^{a}$, Gesine Gunkel-Grabole ${ }^{a}$, Justyna Kowal $^{a}$, \\ Wolfgang Meier ${ }^{a}$, Cornelia G. Palivan ${ }^{a^{*}}$ \\ ${ }^{a}$ Chemistry Department, University of Basel, Mattenstrasse 24a, BPR 10964002 Basel, \\ Switzerland \\ ${ }^{\mathrm{b}}$ Product Design, Mechatronics and Environment Department, Transilvania University of \\ Brasov, 29 Eroilor Blv, 500036 Brasov, Romania
}




\begin{abstract}
Functional surfaces were generated by combination of enzymes with polymer membranes composed of an amphiphilic, asymmetric block copolymer poly(ethyleneglycol)-block-poly $(\gamma$ methyl-e-caprolactone)-block-poly[(2-dimethylamino)ethylmethacrylate]. First, polymer films formed at air-water interface were transferred in different sequences onto silica solid support using the Langmuir-Blodgett technique, generating homogeneous monolayers and bilayers. Detailed characterization of these films provided insight into their properties (film thickness, wettability, topography and roughness). Based on these findings, the most promising membranes were selected for enzyme attachment. Functional surfaces were then generated by adsorption of two model enzymes that can convert phenol and its derivatives (laccase and tyrosinase), well known as high risk pollutants of drinking and natural water. Both enzymes preserved their activity upon immobilization with respect to their substrates. Depending on the properties of the polymer films, different degrees of enzymatic activity were observed: bilayers provided the best conditions both in terms of overall stability and enzymatic activity. The interaction between amphiphilic triblock copolymer films and enzymes is exploited to engineer "active surfaces" with specific functionalities and high efficacy resulting from the intrinsic activity of the biomolecules that is preserved by an appropriate synthetic environment.
\end{abstract}

\title{
KEYWORDS
}

Amphiphilic copolymers, Langmuir-Blodgett, hybrid membranes, bilayers, laccase activity, tyrosinase activity, sensing 


\section{INTRODUCTION}

Nanoscience-based materials and systems offer solutions in a variety of fields such as medicine (drug delivery, diagnostics), catalysis, food- and environmental- sciences and technology. In particular, the combination of synthetic assemblies/membranes with active biomolecules (enzymes, proteins, mimics, nucleic acids) opens up exciting opportunities at the nanoscale such as confined spaces for complex reactions, serving as nanoreactors or artificial organelles, hybrid materials with stimuli-responsive properties, and "active surfaces". ${ }^{1-2}$ In this respect, planar polymer membranes are ideal candidates to attach or insert biomolecules and obtain functional surfaces. ${ }^{3-4}$ They mimic the architecture of phospholipid bio-membranes but provide major advantages like increased mechanical stability, tunable membrane fluidity and thickness and induced stimuli-responsiveness depending on the polymer selected. ${ }^{5}$ Mono-, bi- and multilayer membranes on solid support were based on amphiphilic di- and triblock copolymers that can be generated by a variety of methods: surface-initiated polymerization, vesicle spreading or transfers from the air-water interface by the Langmuir-Blodgett (LB) or Langmuir-Schaefer techniques (LS). ${ }^{6}$ Such solid-supported membranes form thin polymer films that can be used for immobilization of biomolecules either directly by physical adsorption and chemical binding or by encapsulation or entrapment in different assemblies that are attached to the films. ${ }^{5,7}$ Various enzymes, such as laccase, glucose oxidase, or horseradish peroxidase have been used to decorate synthetic thin polymer films. ${ }^{8-10}$ For example, physically adsorbed laccase on copolymer membranes was shown to have higher activity than free laccase in similar conditions, due to the protection by the polymer hydrophilic domain. ${ }^{8}$ Besides, polymer membranes served in various studies as matrices for transmembrane protein incorporation, indicating that polymer membranes are perfectly suitable for interactions with proteins. ${ }^{11-13}$ 
Hybrid assemblies composed of enzymes and polymer membranes benefit from the intrinsic biological activity of the enzymes and the stability of the polymer films, illustrating the potential for applications, such as in production of specific compounds and for biosensing. ${ }^{5}$ A particularly appealing field for applying protein-polymer membranes are the environmental sciences, especially with respect to high water purity where the detection and removal of high risk pollutants is a major challenge. Here, detection and removal of phenols and phenol derivatives is of particular interest as the toxicity levels are usually in the range of $9-25 \mathrm{mg} \mathrm{L}^{-1}$ for both humans and aquatic life. ${ }^{14}$ Lipid films combined with laccase and tyrosinase served for phenol biosensing, ${ }^{15-16}$ but polymeric films provide several advantages due to increased chemical and mechanical stability. ${ }^{17-18}$ Yet, only very few studies provide fundamental insights into the relationship between the molecular properties of the polymer films in relation to the overall activity of the enzymes that is needed in order to design superior hybrid membranes for specific applications.

Here, we focus on the formation of solid supported mono- and bilayer films of asymmetric triblock copolymers, combine them with two enzymes (laccase and tyrosinase) typically used in phenol biosensing ${ }^{15-16}$ and exploit their applicability as functional membranes. We systematically modified the conditions of the combination of biomolecules and solid-supported synthetic membranes in order to identify a stable environment for the enzymes that supports enzymatic activity, providing detailed understanding of film properties required for functional surfaces that can build effective biosensors for phenol derivative detection.

An asymmetric, amphiphilic triblock copolymer poly(ethyleneglycol)-block-poly( $\gamma$-methyl- $\varepsilon$ caprolactone)-block-poly[(2-dimethylamino)ethylmethacrylate] $\left(\mathrm{PEG}_{45}-b-\mathrm{PMCL}_{101}-b-\right.$ PDMAEMA $_{27}, \mathrm{~A}_{45}-\mathrm{B}_{101}-\mathrm{C}_{27}$ ) was selected for this study, because it forms uniform films with a 
high degree of molecular ordering for attachment of laccase ${ }^{8}$ and with increased mechanical stability. ${ }^{17-19}$ The two different hydrophilic blocks are composed of a protein repellent PEG domain and a $\mathrm{pH}$ responsive PDMAEMA domain with tertiary amino groups that is expected to aid adsorption of enzymes. This study goes beyond a previous study of laccase attachment on PEG- $b$-PMCL- $b$-PDMAEMA monolayers, ${ }^{8}$ as it is focused on the accessibility of the immobilized enzymes and the influence of molecular properties of the synthetic films on enzyme immobilization. Various molecular and structural factors: (i) orientation of the asymmetric amphiphilic $\mathrm{ABC}$ block copolymer at air-water interface; (ii) the parameters influencing the mono- and bilayer film formation by the block copolymer at air-water interface and transfer to silica solid support using the Langmuir-Blodgett technique; (iii) the structural properties, which determine the block copolymer film formation and their availability for enzyme immobilization, and (iv) the stability, accessibility and reactivity of the active surface of the enzyme-polymer film were investigated. Different sequences of LB transfer resulting in different architectures ranging from monolayers to bilayers were essential to evaluate the effect of the resulting properties of these films and proteins entrapment on the overall functionality. The influence of these factors serves to obtain a deep insight into the behavior of these hybrid enzyme-polymer films, as an essential step towards generation of efficient and stable functional surfaces.

\section{MATERIALS AND METHODS}

\section{Materials.}

The amphiphilic asymmetric $\mathrm{ABC}$ block copolymer, poly(ethyleneglycol)-block-poly( $\gamma$-methyl$\varepsilon$-caprolactone)-block-poly[(2-dimethylamino)ethylmethacrylate], was synthesized as previously described. ${ }^{20}$ Polished silicon wafers were obtained from Si-Mat Silicon Materials, Germany. 
Laccase from Trametes versicolor, tyrosinase from Mushroom (Agaricus Bisporus), 2,6dimethoxyphenol (DMP), 4-methoxyphenol (4-MP) and solvents (of highest purity grade) were purchased from Sigma-Aldrich. The standard phosphate buffer saline solution (PBS), sodium dodecyl sulfate (SDS) and 3-methyl-2-benzothiazolinone hydrazone (MBTH), $\mathrm{Na}_{2} \mathrm{HPO}_{4} 7 \mathrm{H}_{2} \mathrm{O}$ and $\mathrm{NaH}_{2} \mathrm{PO}_{4}$ used to prepare the phosphate buffer were from Sigma-Aldrich. Bovine serum albumin (BSA) was purchased from Thermo Fisher.

\section{Polymer Film Transfer on Solid Support.}

Polymer films were formed at the air-water interface by closing the LB barriers, which was monitored as previously described by an $\mathrm{EP}^{3} \mathrm{SW}$ system (Nanofilm Technologie GmbH, Göttingen, Germany) equipped with a Nd-YAG laser $(\lambda=532 \mathrm{~nm})$, long distance objective (Nikon, 20x) and monochrome CCD camera. ${ }^{8}$ The size of the Brewster angle microscopy (BAM) image is $220 \times 250 \mu \mathrm{m}^{2}$, with a resolution of $1 \mu \mathrm{m}$. The transfer of the block copolymer films onto the silica solid support was performed using the Langmuir-Blodgett (LB) technique, following the previously described procedure using a Mini-trough (KSV Instruments, Finland). In brief, the silica slides were cut into pieces of approx. $1 \mathrm{~cm}^{2}$ and then cleaned by ultrasonication in chloroform (three times, 15 minutes each time). For the "down" transfer, the silica slides were placed in the air subphase, the polymer film was formed and transferred onto the silica slide by dipping the LB dipper into the water. In order to avoid uncontrolled film deposition or contamination the water surface was cleaned after "down" dipping transfer prior to lifting the silica slides from the water subphase.

\section{Copolymer Monolayer and Bilayer Films Characterization.}

The dry thickness of the polymer monolayer and bilayer films were measured on two different slides (at least five individual measurements on each) and average values with standard deviation 
were calculated for values determined with a mean squared error (MSE) below 1. Film thickness was measured with $\mathrm{EP}^{3} \mathrm{SW}$ imaging ellipsometer (Nanofilm Technologie GmbH, Göttingen, Germany). The thickness of the silicon dioxide layer $(\sim 2 \mathrm{~nm})$ was taken into account and measurements were performed for ten incident angles ranging from $55^{\circ}$ to $75^{\circ}$, with 1.5 refractive index value used for the polymer, using the nk_fix model. The wetting properties of the polymer films were investigated with a contact angle goniometer, CAM 100 (LOT quantum design) using a CDD camera with $50 \mathrm{~mm}$ optics. The measurements were performed by placing droplets of ultrapure water with a micro-syringe on the solid supported films, images were then recorded and analyzed by automatic curve fitting performed by the instrument software. The drop volume was kept constant for all measurements, measurements were taken on two different slides (five different areas on each) and average values and standard deviation were calculated. The topography of the polymer films on silica slides was investigated by atomic force microscopy (AFM) using a JPK NanoWizard® 3 AFM (JPK Instruments AG). All measurements were carried out in the AC mode in air, using silicon cantilevers (PPP-NHCR, Nanosensors) with a nominal spring constant of $10-130 \mathrm{~N} \mathrm{~m}^{-1}$ and a resonance frequency of $300 \mathrm{kHz}$. The images were analyzed with the data analysis software JPK Data Processing (v. 5.0).

\section{QCM Measurements of Enzyme Adsorption on Polymer Films.}

The adsorption of the enzymes on polymer films was studied with a quartz crystal microbalance with dissipation (QCM-D) system Q-Sense E1 (Biolin Scientific, Sweden). The block copolymer monolayer and bilayer films were first transferred to silicon dioxide QCM-D sensor chips (5 MHz quartz crystal q-sense, Biolin Scientific) by the LB technique using the mini-trough and then placed in the QCM-D chamber. The QCM-D sensor was stabilized under buffer flow until the frequency signal fluctuation was below $\pm 1 \mathrm{~Hz}$. After system stabilization, solutions of $0.5 \mu \mathrm{g}$ 
$\mathrm{mL}^{-1}$ laccase (in phosphate buffer, $\mathrm{pH} 7$ ) or $0.5 \mu \mathrm{g} \mathrm{mL} \mathrm{m}^{-1}$ tyrosinase (in PBS, $\mathrm{pH} 7$ ) were introduced into the QCM-D chamber with the flow speed of $100 \mu \mathrm{L} \mathrm{min}{ }^{-1}$. The enzyme was allowed to adsorb for 1-2 hours until signal fluctuations were less than $\pm 1 \mathrm{~Hz}$, incubated for further $30 \mathrm{~min}$ before washing thoroughly with the appropriate buffer solution. The enzyme adsorption and desorption stages (washing) are performed under the same constant slow flow $\left(100 \mu \mathrm{L} \mathrm{min}^{-1}\right)$ of enzyme solution and buffer, respectively, for several hours. The change in resonance frequency value $(\Delta \mathrm{f})$ measured with overtone 5 is used to calculate the mass $(\Delta \mathrm{m})$ adsorbed onto the polymer film, based on Sauerbrey equation $(\Delta \mathrm{m}=-\mathrm{C} \Delta \mathrm{f}$, where $\mathrm{C}=17.7 \mathrm{ng}$ $\mathrm{cm}^{-2} \mathrm{~Hz}^{-1}$ is a constant, depending on the quartz QCM-sensor properties. ${ }^{21}$

\section{Enzyme Adsorption on Polymer Films.}

Immobilization of enzymes on polymer films was performed after the film transfer onto the solid support, in conditions similar to that used for the QCMD experiments (enzyme adsorption, incubation and desorption). Silica slides with transferred mono- or bilayers of block copolymer were immersed in enzyme solutions $\left(0.5 \mu \mathrm{g} \mathrm{mL} \mathrm{m}^{-1}\right.$ for both laccase and tyrosinase, the first in in phosphate buffer $50 \mathrm{mM}, \mathrm{pH} 7$, the second in PBS buffer $\mathrm{pH} \mathrm{7)} \mathrm{for} 2 \mathrm{~h}$ under shaking (dynamic regime), incubation for 30 min without shaking (static regime), then rinsed with the buffer for 1 h (dynamic regime).

\section{Bicinchoninic Acid Assay.}

The concentrations of enzymes adsorbed on polymer films were determined by a bicinchoninic acid assay (BCA assay, Micro BCA ${ }^{\mathrm{TM}}$ Protein Assay Thermo Fisher). Prior to the assay, the enzymes were desorbed from the polymer films by incubation with sodium dodecyl sulfate (SDS, $5 \mathrm{wt} \%$ ) under shaking for $2 \mathrm{~h}$, adapted from Gunkel et al. ${ }^{22}$ The enzyme concentration of the supernatant solution was determined using a calibration curve obtained with bovine serum 
abumin (BSA, $0.5-20 \mu \mathrm{g} \mathrm{mL} L^{-1}$ ). As the enzyme concentration in solution was $0.1-0.3 \mu \mathrm{g} \mathrm{mL}^{-1}$, the surface area was increased by using two silica plates with polymer films $\left(8.75 \mathrm{~cm}^{2} /\right.$ plate $)$ for one measurement. The amounts of desorbed proteins were quantified, calculating averages determined with the two silica plates and from 4 repeated measurements.

\section{Activity of Free and Immobilized Enzymes.}

The enzymatic activity of laccase in solution $\left(0.1-0.3 \mu \mathrm{g} \mathrm{mL} L^{-1}\right)$ was studied using 2,6dimethoxyphenol (DMP) as substrate (0.1 mM DMP in $50 \mathrm{mM}$ phosphate buffer, $\mathrm{pH}$ 7). DMP forms an oxidation product that allows spectrophotometric detection at $\lambda_{\max }=470 \mathrm{~nm}^{23}$ Similarly, the laccase-polymer functionalized surfaces were placed into 24 well plates and a solution of $0.1 \mathrm{mM}$ DMP (in $50 \mathrm{mM}$ phosphate buffer, $\mathrm{pH}$ 7) was added. Enzymatic activity was monitored by spectrophotometric measurements of the supernatant solution. Four replicates of different solid supported films were used. The activity of tyrosinase in solution $\left(0.1-0.3 \mu \mathrm{g} \mathrm{mL}^{-1}\right)$ was investigated spectrophotometrically with $0.2 \mathrm{mM}$ 4-methoxyphenol (4-MP) as a substrate and $2.5 \mathrm{mM}$ 3-methyl-2-benzothiazolinone hydrazone hydrochloride (MBTH) as a dye at $\lambda_{\max }=$ $492 \mathrm{~nm}$. The tyrosinase-polymer functionalized surfaces were placed into 24 well plates and a solution of $0.2 \mathrm{mM}$ 4-MP and $2.5 \mathrm{mM}$ MBTH (in $50 \mathrm{mM}$ phosphate buffer, $\mathrm{pH}$ 7) was added and the activity was measured using the supernatant. For the calculation of the end concentration of the product, the substrates (DMP and 4-MP, respectively) were reacted with an excess of the enzyme (laccase and tyrosinase, $0.2 \mathrm{mg} / \mathrm{ml}$ ). The product formation was monitored by UV-vis to determine full conversion. Subsequently, the product solution was diluted to the concentrations used in the calibration curve. For the calculation of enzyme activity, the wash solutions after enzyme immobilization were collected and the activity was measured and subtracted from the activity of the start solution. The difference was then assumed to be enzyme immobilized on the 
surface and compared to measured activity of the immobilized enzymes. UV-Vis spectra were recorded at $\lambda_{\max }=492 \mathrm{~nm}$ or $\lambda_{\max }=470 \mathrm{~nm}$ in the wavelength range $200-800 \mathrm{~nm}$ (with an accuracy of $1 \mathrm{~nm}$ ) using Quartz cuvettes on a Specord 210 Plus (analytik Jena Edition 2010) and a Thermo Scientific NanoDrop 2000c.

All other reagents and methodologies are detailed in the text, figures legends or tables footnotes.

\section{RESULTS AND DISCUSSIONS}

\section{Formation of asymmetric polymer membranes on solid support.}

Planar polymer membranes on solid support were prepared with an amphiphilic asymmetric ABC triblock copolymer $\mathrm{PEG}_{45}-b-\mathrm{PMCL}_{101}-b$-PDMAEMA 27 , poly(ethyleneglycol)-block$\operatorname{poly}(\gamma$-methyl-e-caprolactone)-block-poly[(2-dimethylamino)ethylmethacrylate]. The morphology and properties of the mono- and bilayer polymer membranes were investigated with respect to their interaction with functional biomolecules.

The compression of polymer films at the air-water interface was monitored by Brewster angle microscopy (BAM) before transferring the films on solid support by the Langmuir-Blodgett technique as schematically illustrated in Figure 1. The transfer to silica slides was performed at surface pressure $(\Pi)$ values below the collapse pressure $\left(26 \mathrm{mN} \mathrm{m}^{-1}\right)$. All polymer films were obtained with a transfer ratio of about 1 , indicating a transfer yield close to $100 \%$, with uniform deposition of the polymer onto the silica support. During Langmuir compression the copolymer undergoes different phase transitions, starting with a "pancake" conformation (Figure 1.A), followed by "mushroom" and "brush-like" arrangements, in which small lateral interactions force the water soluble polymer blocks to coil (Figure 1 B, and E.a,b.c). At higher surface pressures, the copolymers adopt a more ordered "cigar-like" conformation, and the final 
conformation corresponds to a highly packed monolayer film formed at the collapse point Figure $1 \mathrm{C}$, and E.d). ${ }^{24}$ To tune the interactions with enzymes, polymer films with different directions and transfer sequences were prepared. Indeed, different directions and transfer sequences are expected to induce formation of polymer films with different architectures, which will affect the properties of these films and the resulting entrapment and accessibility of the enzymes. Different transfer directions were used, "up" means the silicon substrate was moved up from the water subphase to the air subphase and the inverse direction is called "down" transfer. The resulting polymer films based on single transfers are labeled up and down, respectively, and combinations of two transfers are labeled accordingly down-down, up-down, down-up or up-up (Figure 2.A). 
A

A

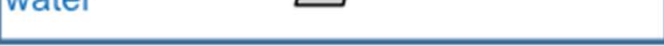

B

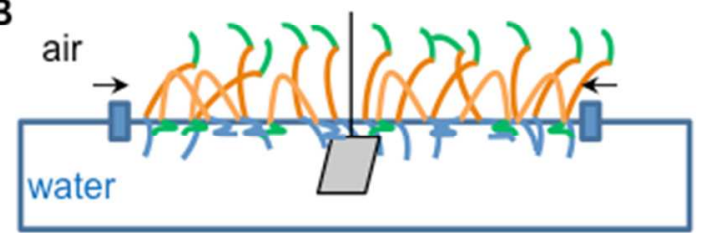

C

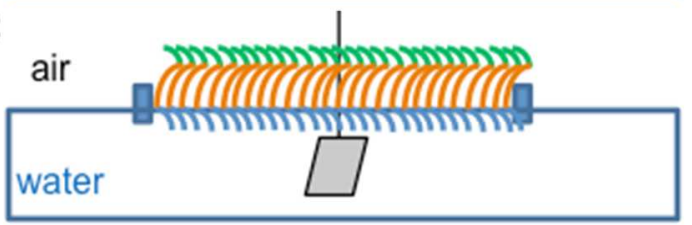

E

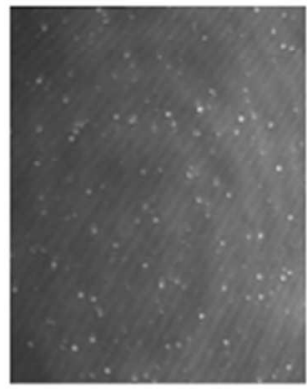

a

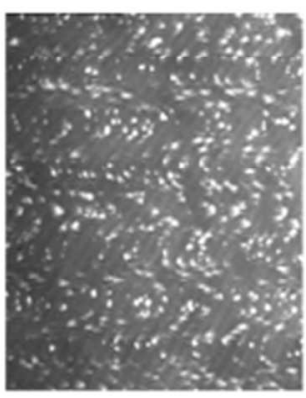

b

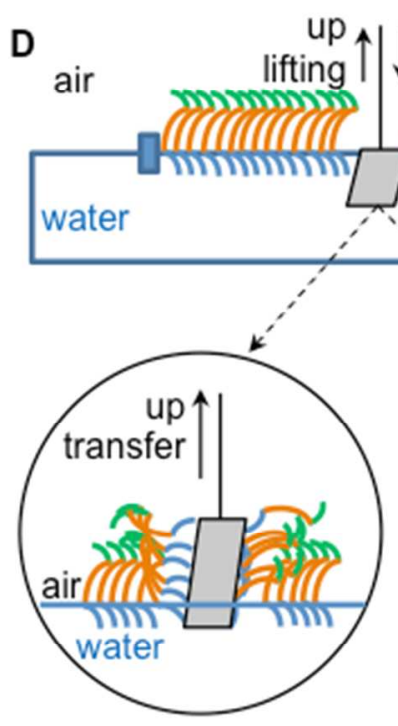

a

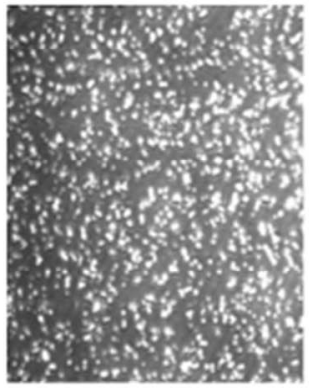

C

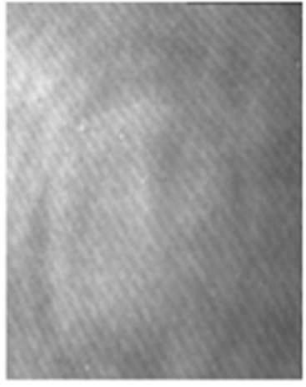

d

Figure 1. $\mathrm{PEG}_{45}-b-\mathrm{PMCL}_{101}-b$-PDMAEMA 27 copolymer used for solid supported membranes preparation. A to D principle of the Langmuir-Blodgett transfer technique: A - polymer spread at air-water interface; B - polymer film organization at air-water interface; $\mathrm{C}$ - polymer film compressed at air-water interface; $\mathrm{D}$ - polymer transfer onto a hydrophilic solid support ( $\mathrm{a}$ - up transfer, up lifting; $\mathrm{b}$ - down transfer, down dipping); E - Brewster angle 
A
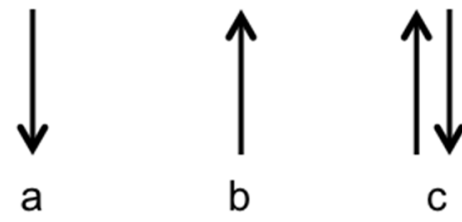

b

C

B

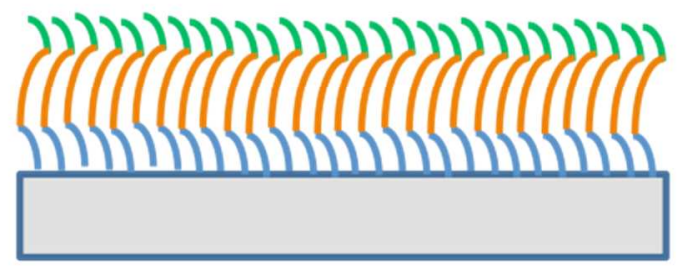

a

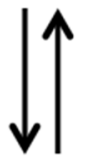

d

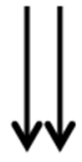

e

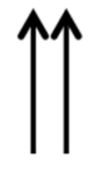

f

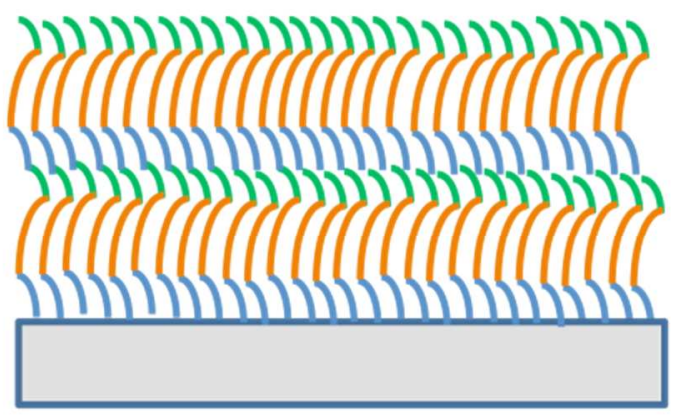

b

Figure 2. LB transfers to generate the polymer films: A - transfer directions ( $\mathrm{a}$ - down transfer, down dipping; $\mathrm{b}$ up transfer, up lifting; c - up-down transfer; $\mathrm{d}$ - down-up transfer; e - down-down transfer; $\mathrm{f}$ - up-up transfer); $\mathrm{B}$ films resulting from specific transfers ( $a$ - monolayer film; $b$ - bilayer film). 
Earlier studies revealed that during "up" transfer the PEG block is adsorbed on the solid silica surface and the PDMAEMA block is oriented outside. ${ }^{8}$ This equips the solid supported polymer membranes with stimuli-responsive behaviour as PDMAEMA is $\mathrm{pH}$ responsive. ${ }^{25}$ Additional interesting properties are expected for bilayer morphologies, where the monolayer acts as a new "substrate" for the second transfer, because it has been described that the interaction between such films leads to considerable rearrangements. ${ }^{26}$ Hence, a detailed insight into the morphology of these mono- and bilayer polymer membranes is necessary in order to understand interaction of the films with enzymes.

The thickness of the $\mathrm{A}_{45}-\mathrm{B}_{101}-\mathrm{C}_{27}$ films is correlated with the number of layers and the type of transfer and thus thickness measurements can indicate successful transfer of the polymer to the substrate. The film thickness as determined by spectroscopic ellipsometry increased following the order of polymer transfers on the solid support: down-down transfer $<$ up-down transfer $<$ down-up transfer $<$ up transfer (monolayer) < up-up transfer (bilayer) (Figure 3.A). In addition, the surface hydrophilicity was determined to ensure favorable conditions for interaction between enzymes and the $\mathrm{A}_{45}-\mathrm{B}_{101}-\mathrm{C}_{27}$ block copolymer films. Static water contact angles (CA) for all $\mathrm{A}_{45}-\mathrm{B}_{101}-\mathrm{C}_{27}$ films are below $90^{\circ}$ (Figure 3.A), therefore all polymer films on silica slides possess a hydrophilic surface. ${ }^{27}$ Further, these findings indicate that the triblock copolymer chains are arranged at the air-water interface with a hydrophilic block oriented towards air. Based on our previous results that showed that the $\mathrm{C}$ block is oriented to the air subphase in up monolayers, it is deduced that the combined double transfers behave similarly and the PDMAEMA block is oriented upwards. ${ }^{8}$ Moreover, the interaction of the polymer membranes with the enzymes is also governed by the surface roughness (Figure 3.B), a high roughness translates to a larger surface area available for interaction of biomolecules. The membrane 
topography and the root mean square roughness $(\mathrm{Rq})$ were determined by atomic force microscopy measurements. $\mathrm{Rq}$ was selected as it is more sensitive to large deviations with respect to the mean than other roughness parameters. ${ }^{28}$ All polymer films except the down and down-down transfer formed membranes of a few nanometers roughness, increasing with the number and direction of Langmuir-Blodgett transfers (Table S1, Supporting Information). The stability of the mono- and bilayer polymer membranes was evaluated by comparison of the film topography of freshly prepared films with samples stored at room temperature in air for one week and three months, respectively. (Figure S1, Supporting Information). Importantly, no considerable topographical differences were detected for any of the transfer sequences, underlining the long-term stability and the application potential as long-lived soft synthetic surfaces.

The "up" transfer yielded a monolayer with a dry thickness of $5.3 \pm 0.4 \mathrm{~nm}$ and a static water contact angle $(\mathrm{CA})$ value of $73 \pm 1^{\circ}$, which shows a clear change from a silica substrate $\left(33 \pm 3^{\circ}\right)$ (Figure 3). The surface roughness was $1.08 \pm 0.04 \mathrm{~nm}$ (Table S1, Supporting Information). For "down" and "down-down" transfers the data indicates that polymer membranes could not be formed, the thickness was negligible $(0-0.4 \pm 0.1 \mathrm{~nm})$ and the contact angles were not significantly different after "down" transfer $\left(39^{\circ} \pm 0.1^{\circ}\right)$ compared to the bare silica substrate. This may be explained by the orientation of the polymer chains, since both B and C blocks will interact with the substrate (as opposed to the A block in "up" transfers). Hence, the interaction with the substrate is governed by repulsion from the B block and attraction from the $\mathrm{C}$ block, and it appears the repulsion was stronger than attractive forces and thus membranes could not be formed. 
A

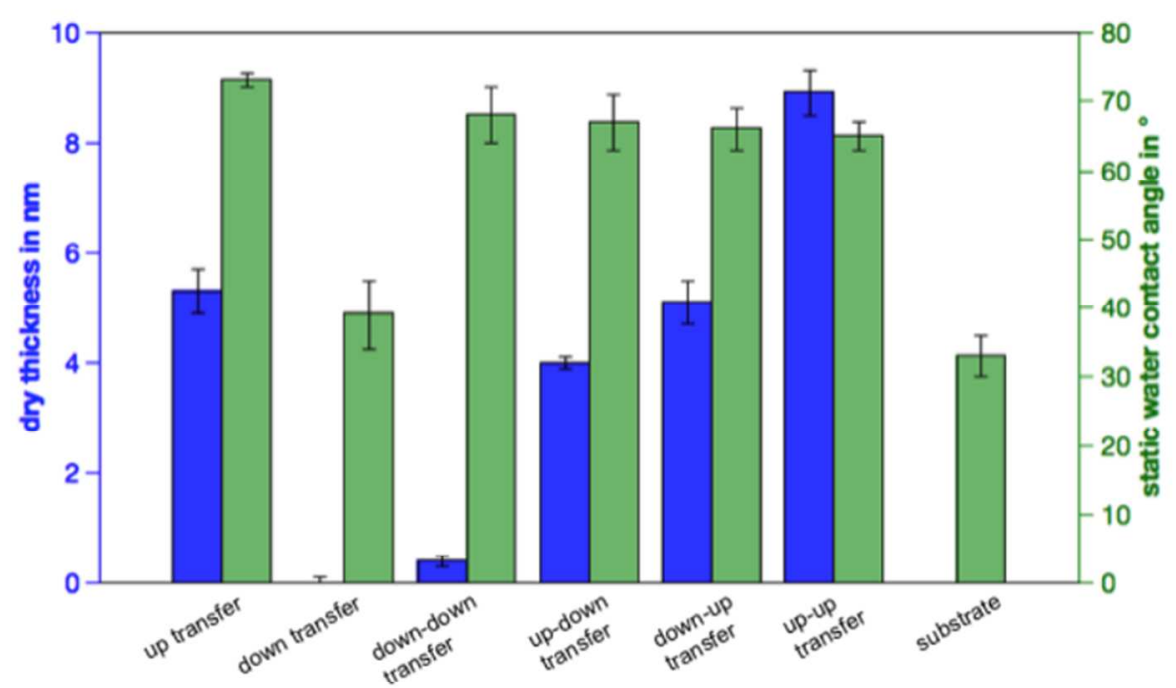

B
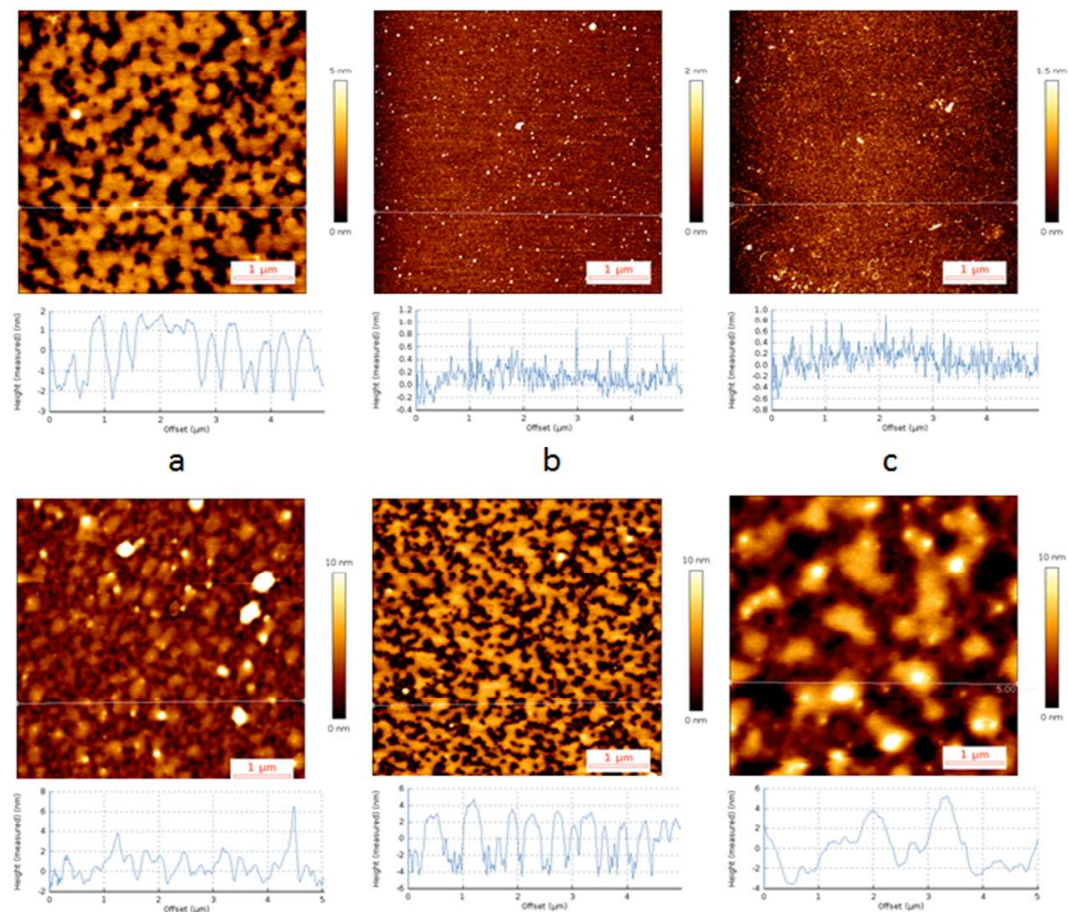

d

e 
Figure 3. Characterization of different solid supported $A_{45}-B_{101}-C_{27}$ copolymer films: $A$ - thickness and wettability; B - AFM images (AC mode in air) with different transfer types and their height profiles (a - up transfer, monolayer film formed; $\mathrm{b}$ - down transfer, no film formation; c - down-down transfer, no film formation; d - down-up transfer, down-up monolayer film formed; e - up-down transfer, up-down monolayer film formed; f - up-up transfer, bilayer film formed).

Polymer films obtained after "up-down" and "down-up" transfers possess a dry thickness of $4.0 \pm 0.1 \mathrm{~nm}$ and $5.1 \pm 0.4 \mathrm{~nm}$, respectively. These values are similar to the thickness of the monolayer film, which suggests that a monolayer-based membrane was formed (up-down monolayer and down-up monolayer). This further underlines that only an "up" transfer leads to a successful membrane formation on silica support. However, the roughness of the membrane increases $(2.35 \pm 0.07 \mathrm{~nm}$ for up-down monolayer), suggesting interaction or rearrangements of the polymer membrane during a second transfer. Importantly, both up-down and down-up monolayers possess a hydrophilic surface as confirmed by their CA values of $66 \pm 3^{\circ}$ and $67 \pm 4^{\circ}$ respectively. In the case of the "up-up" transfer, the film thickness is almost twice $(8.9 \pm 0.4 \mathrm{~nm})$ in comparison with the monolayer film, indicating formation of a bilayer membrane. This is further supported by the membrane wettability $\left(65 \pm 2^{\circ}\right)$ and an increase in roughness $(4.30 \pm$ $0.48 \mathrm{~nm})$.

We introduce the following terminology for the polymer membranes formed by the amphiphilic asymmetric block copolymer based on the preparation method and the results discussed above: monolayer for membranes prepared by "up" transfer, bilayer for "up-up" transfer, up-down monolayer (“up-down”) and down-up monolayer (“down-up”). In contrary to z- and y-type lipid films, this terminology describes the preparation more precisely and allows to relate the preparation method directly with the interaction with the enzymes. ${ }^{29}$ 


\section{Adsorption of Enzyme on Copolymer Membranes.}

The three most promising solid supported polymer membranes monolayer, up-down monolayer and bilayer were selected for further studies regarding adsorption of two different enzymes, laccase and tyrosinase. Laccase has a molecular weight of $96 \mathrm{kDa}$ and dimensions of $4.5 \mathrm{~nm} \times$ $5.5 \mathrm{~nm} \times 6.5 \mathrm{~nm},{ }^{30}$ while tyrosinase is larger with $120 \mathrm{kDa}$ and is $10.4 \mathrm{~nm} \times 10.45 \mathrm{~nm} \times 10.84$ nm in size. ${ }^{31}$ Enzyme adsorption on the different types of solid supported polymer membranes was investigated by quartz crystal microbalance (QCM-D) (Figure 4), as this method allows calculation of the mass of adsorbed enzyme on the membrane surface.
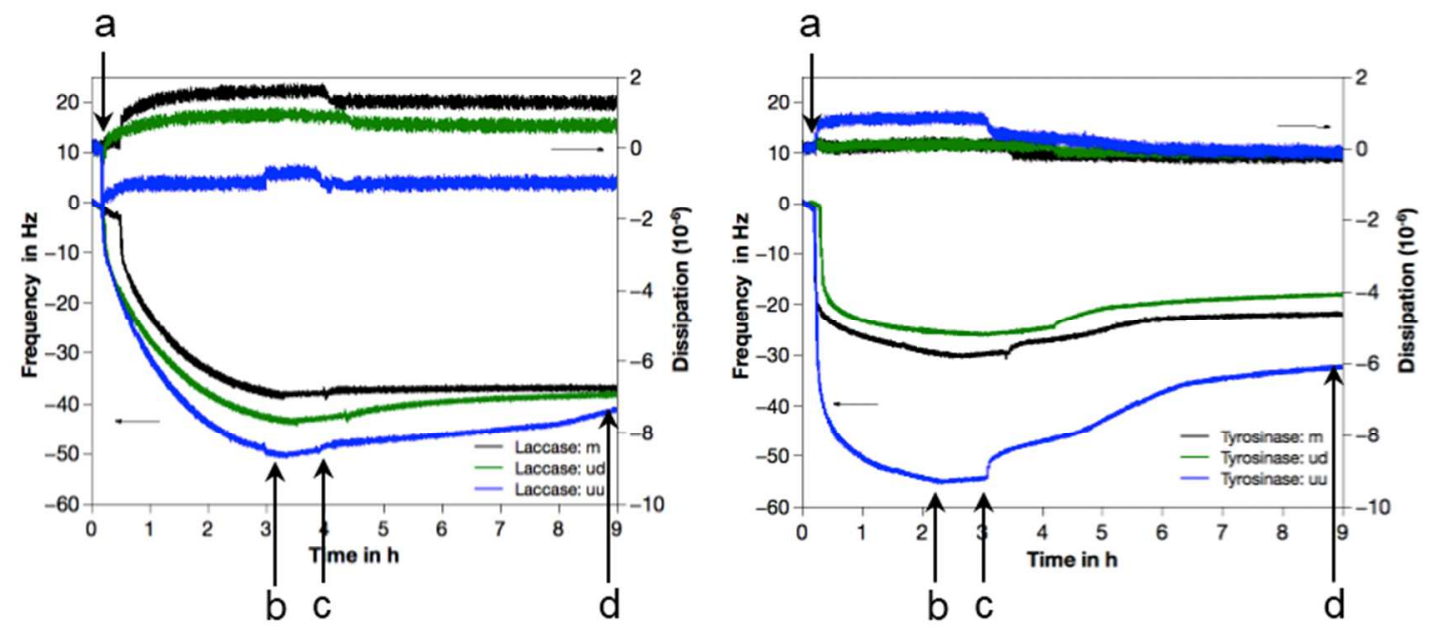

Figure 4. Changes in frequency (mass) and dissipation during the adsorption-incubation-desorption of laccase (left) and tyrosinase (right). Stages of enzymes adsorption: a - system stabilization (buffer flow); b - enzyme adsorption (enzyme flow); c - enzyme incubation (no flow); d - enzyme desorption (buffer flow). Both enzymes $\left(0.5 \mu \mathrm{g} \mathrm{mL}^{-1}\right)$ adsorbed on polymer membranes: monolayer (m); up-down monolayer (ud) or bilayer (uu). QCM graphs shown are from the $5^{\text {th }}$ overtone.

Our data was suitable for analysis with the Sauerbrey equation, as the change in dissipation was very small and the condition for dissipation (D) to frequency (F) ratio $\Delta \mathrm{D}_{\mathrm{n}} /\left(-\Delta \mathrm{F}_{\mathrm{n}} / \mathrm{n}\right) \ll 410^{-7} \mathrm{~Hz}^{-}$ 
${ }^{1}$ is fulfilled (average value of $\sim 0.0410^{-7} \mathrm{~Hz}^{-1}, \mathrm{n}=5,5 \mathrm{MHz}$ crystal). ${ }^{21}$ Hence, the frequency difference is proportional to the adsorbed mass and the film is considered to be rigid. ${ }^{32}$

We evaluated the changes in frequency $(\mathrm{F})$ during the enzyme adsorption on different polymer films in four stages as indicated by arrows in Figure 4: (a) system stabilization, with constant F under buffer flow (10-20 minutes), (b) enzyme adsorption, F decreases under enzyme flow (2-3 hours), (c) enzyme incubation without flow, F almost constant (30 minutes), (d) enzyme desorption, $\mathrm{F}$ increases under buffer flow until stable again, suggesting that no more enzyme is desorbing. The adsorption of laccase on monolayer (up and up-down) and bilayer (up-up) films occurred during 3 hours. After the incubation, less laccase was desorbed under buffer flow from monolayers than from the bilayer (Figure S2, Supporting Information). No significant influence of the film type on the deposited mass of laccase was observed, the enzyme was adsorbed on all three types of polymer films in a range of $0.562-0.632 \mu \mathrm{g} \mathrm{cm}^{-2}$ (Figure 5, Table S2). Enzyme molecular weights were taken into account to determine the surface coverage as $\Delta \mathrm{m} / \mathrm{MW}$ ratio, and the number of enzymes adsorbed per area of polymer film. ${ }^{33}$ For tyrosinase, adsorption ended earlier (2 hours) and less enzyme was adsorbed on the monolayer films, whilst considerably more was adsorbed on the bilayer film $\left(0.708 \mu \mathrm{g} \mathrm{cm}^{-2}\right)$. After incubation, tyrosinase desorption under buffer flow was more prominent than for laccase, thus at the end less tyrosinase than laccase remained adsorbed on the films. The enzyme dimensions are expected to influence the adsorption-desorption process. Indeed, a lower quantity of the larger enzyme tyrosinase, was finally adsorbed on the polymer membrane surface, which may be explained by requiring more space per molecule on the synthetic membrane. 

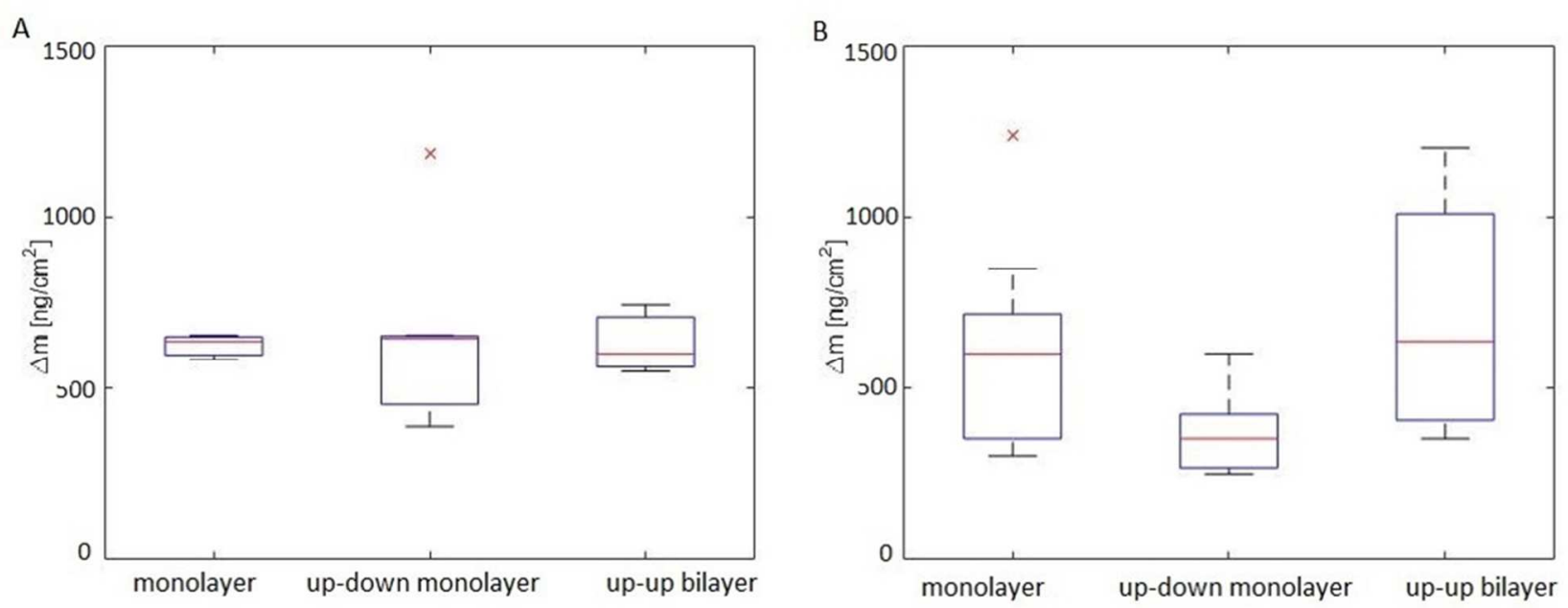

Figure 5. Amount of laccase (A) and tyrosinase (B) in $\mathrm{ng} / \mathrm{cm}^{2}$ calculated from QCM-D and shown in a boxplot with $n=3-6$.

Another factor affecting the enzyme immobilization process in the case of tyrosinase as compared to laccase is the tyrosinase tetramer structure, adopting a less compact configuration when adsorbing on the synthetic membrane. ${ }^{31}$ This explains why the type of polymer film (mono/bilayer film, up/down transfer) influenced the enzyme immobilization for tyrosinase more than for laccase. Our results are in agreement with studies where tyrosinase was deposited on lipid-based membranes prepared by Langmuir-Schaefer technique (horizontal lifting). ${ }^{17}$

The successful attachment of both enzymes on polymer films (monolayers and bilayer) is based on an electrostatic interaction between the enzymes and the exposed domain of the polymer films. PDMAEMA, which is the exposed C block of our polymer membranes, is positively charged at a pH between 5 and 8 due to protonation of the tertiary amino groups. ${ }^{34}$ Both, laccase and tyrosinase are negatively charged in the $\mathrm{pH}$ range used, (laccase above $\mathrm{pH} 3.5^{30}$ and tyrosinase above $\mathrm{pH}$ 4.7, Sigma - Datasheet). Hence, it is deduced that the electrostatic 
interaction is key to the adsorption of these enzymes on the synthetic mono- and bilayers. An influence of the surface charge on the adsorption of laccase on positively charged methylene blue self-assembled monolayer films has been observed in other studies as well. ${ }^{23}$ The adsorptiondesorption behavior suggests that both adsorption and desorption of both enzymes differs with the membrane type and enzyme. The adsorbed mass of laccase and tyrosinase on polymeric membranes remained stable for at least $18 \mathrm{~h}$ (Figure S2, Supporting Information) at room temperature.

\section{Active Surfaces Generation with Immobilized Enzymes on Copolymer Membranes.}

Enzyme adsorption on the polymer films for activity tests was performed by immersion of the $\mathrm{A}_{45}-\mathrm{B}_{101}-\mathrm{C}_{27}$ solid supported monolayer/bilayer films in enzyme solutions. AFM images of the $\mathrm{A}_{45} \mathrm{~B}_{101} \mathrm{C}_{27}$ triblock copolymer films with adsorbed laccase and tyrosinase, respectively, did not show significant differences when measured immediately, after 1 day and after 3 months (Figure S3, Supporting Information). Long-term stability of these active surfaces supports their further application and is discussed below.

In order to determine the amount of the enzymes immobilized on the $A_{45}-B_{101}-C_{27}$ solid supported copolymer films, the bicinchoninic acid (BCA) assay was used. The BCA assay allows to quantify the amount of proteins in solution, hence the enzymes were first desorbed from the polymer films using SDS, contrary to the total enzyme amount adsorbed as determined by QCM-D. The concentration of SDS (5 wt $\%$ ) used for enzyme desorption was in the range where the results obtained by the BCA assay are not affected, as stated by the supplier. The data obtained with BCA assay for both enzymes is presented in Figure 6. In the case of laccase, the amounts of desorbed enzyme available for BCA assay quantification are smaller than the amount of adsorbed laccase, probably due to incomplete removal of the enzyme by SDS. This indicates 
that not all laccase molecules are accessible, a fraction that cannot be removed remains embedded in the polymer film.

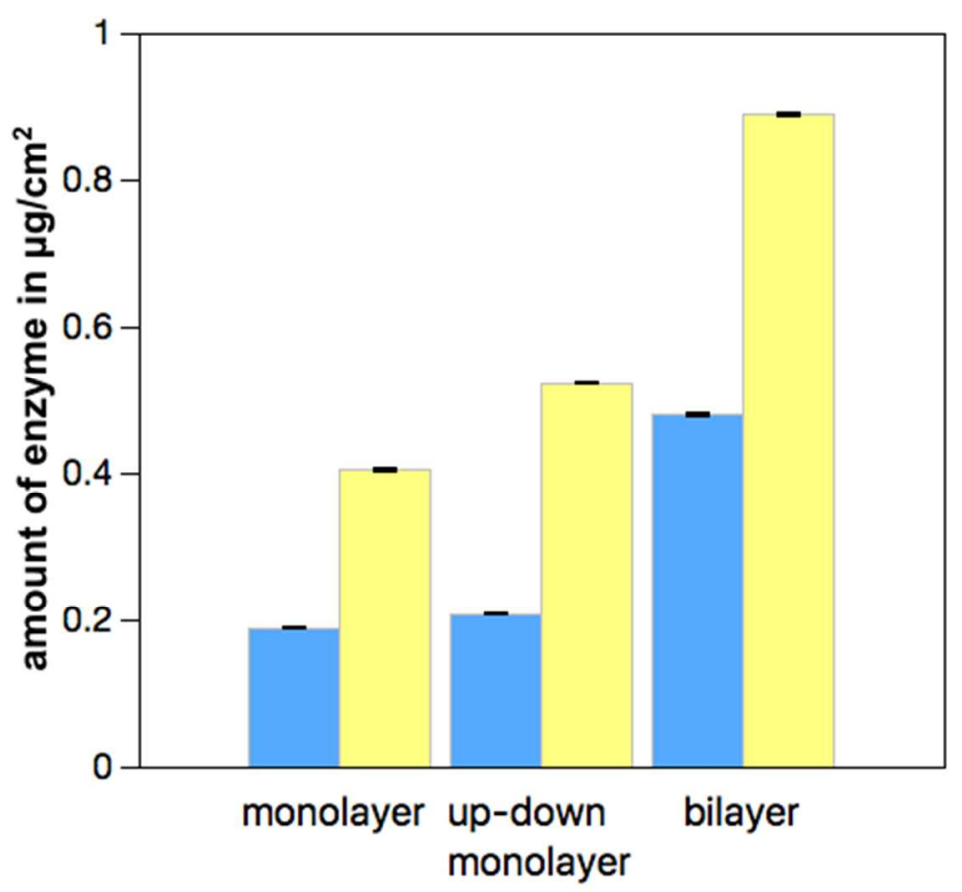

Figure 6. Amounts of laccase (blue) and tyrosinase (yellow) removed from the monolayer, up-down monolayer and bilayer polymer films, measured by BCA assay. The determined mass of the enzymes was expressed as mass per surface area $\left(\mu \mathrm{g} \mathrm{cm}^{-2}\right)$.

Interestingly, whilst the amount of immobilized laccase is approximately similar for all layer types, as determined by QCM-D, the accessibility determined by the BCA assay varies with the type of polymer film. Both monolayers (monolayer and up-down monolayer) have lower concentrations of accessible laccase than the bilayer. For the monolayer films, the values of removed laccase of $0.189 \pm 0.001 \mu \mathrm{g} \mathrm{cm}^{-2}$ (monolayer), and $0.209 \pm 0.001 \mu \mathrm{g} \mathrm{cm}^{-2}$ (up-down monolayer) are significantly lower than what was obtained for the bilayer films $(0.479 \pm 0.003$ $\mu \mathrm{g} \mathrm{cm}^{-2}$ ). A similar behavior has been observed for tyrosinase, with less enzyme detected in the 
case of monolayers $\left(0.405 \pm 0.002 \mu \mathrm{g} \mathrm{cm}^{-2}\right.$ for monolayer and $0.521 \pm 0.001 \mu \mathrm{g} \mathrm{cm}{ }^{-2}$ for updown monolayer) than in the case of the bilayer $\left(0.888 \pm 0.001 \mu \mathrm{g} \mathrm{cm}^{-2}\right)$. This observation can be explained by a higher roughness and therefore a larger surface area of the bilayer, which makes the immobilized biomolecules more accessible. A higher amount of tyrosinase was removed according to the BCA assay compared to what was obtained by QCM-D. This unexpected behavior might be related to differences in the adsorption-desorption procedures of these methods and intrinsic properties of tyrosinase (conformation, charge, interaction with the synthetic membrane). Besides, the measurement principles are very different and for the BCA assay also affected by the accessibility of the enzymes, complicating an immediate comparison. Importantly, both QCM-D and BCA assay confirm that laccase and tyrosinase adsorb on the different types of polymer films, a prerequisite for the development of a biosensors based on the specific enzyme activities. .

\section{Enzymatic Activity on Polymer Membranes.}

The enzymatic activity of laccase and tyrosinase adsorbed on polymer monolayer and bilayer membranes was studied and compared with the activity of free enzymes. The activities were studied with phenol derivatives as models to assess the biodetection of phenols by our active surfaces, 2,6-dimethoxyphenol (DMP, $0.1 \mathrm{mM}$ ) in the case of laccase and 4-methoxyphenol (4MP, $0.2 \mathrm{mM}$ ) for tyrosinase. The activity of both enzymes free in solution increased with the enzyme concentration (0.1-0.3 $\mu \mathrm{g} \mathrm{mL}^{-1}$ ) (Figure S4, Table S3, Supporting Information) and maximum activity of laccase free in solution was reached after $24 \mathrm{~h}$, while tyrosinase free in solution reached a maximum after $1 \mathrm{~h}$. Therefore, the activity of the immobilized enzymes on the copolymer mono- and bilayer films was tested for different time periods, laccase for $24 \mathrm{~h}$ (with maximum activity at 19-24 h) and tyrosinase for $6 \mathrm{~h}$ (with maximum activity at 2-3 h). The 
activity increased starting from enzymes immobilized on monolayer to up-down monolayer, with the enzymes immobilized on bilayer showing the highest activity (Figure 7 A, B, Figure S5 Supporting Information). Thereby, for laccase the maximum concentration for the product was detected after $24 \mathrm{~h}$ on the bilayer $(1.05 \pm 0.55 \mu \mathrm{M})$, compared to the monolayer, where the maximum was after $19 \mathrm{~h}(0.39 \pm 0.26 \mu \mathrm{M})$. For tyrosinase the highest concentration of formed product on the monolayer was detected after $4 \mathrm{~h}(21.33 \pm 7.35 \mu \mathrm{M})$ and for the bilayer after $2 \mathrm{~h}$ $(35.38 \pm 6.09 \mu \mathrm{M})$ (Figure S6, Table S4 Supporting Information). In literature these reactions are well known and the mechanisms described. ${ }^{35-36}$ This activity behavior correlated well with the concentration of accessible enzymes on the bilayer film as determined by BCA assay. As the highest activity of laccase and tyrosinase has been obtained for the enzymes immobilized on bilayer, we used the bilayer films to get more insight into the the phenol derivative detection range by decreasing 10 -fold the concentration of the enzymes substrate (Figure $7 \mathrm{C}$ ). The autooxidation of the enzyme substrates has been taken into account as a background correction, that has been performed for all curves by subtraction of the absorption intensity obtained when the enzyme substrate was added to the polymer membrane. The 10-fold decrease of the enzyme substrates concentration decreased the enzymatic activity only slightly, indicating that lower concentrations of phenol derivatives can be efficiently detected by our functional surfaces (with $0.01 \mathrm{mM}$ laccase substrate concentration and $0.02 \mathrm{mM}$ tyrosinase substrate concentration). Importantly, the concentration of remaining substrate, which acts as a model for phenol contaminants, is reduced by $50 \%$ for tyrosinase and $10 \%$ for laccase. This further highlights the potential of the hybrid membranes for sensing and detection applications. 
A
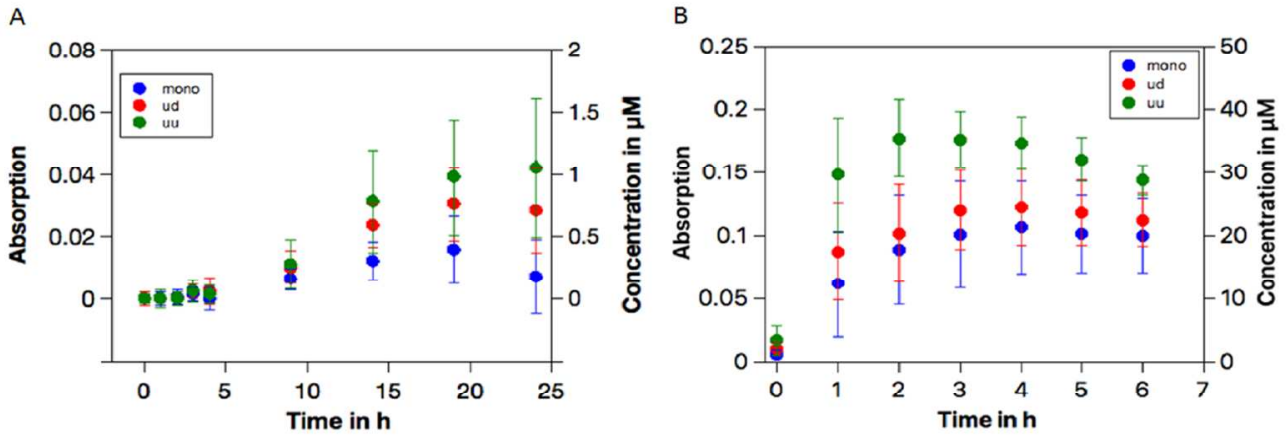

C

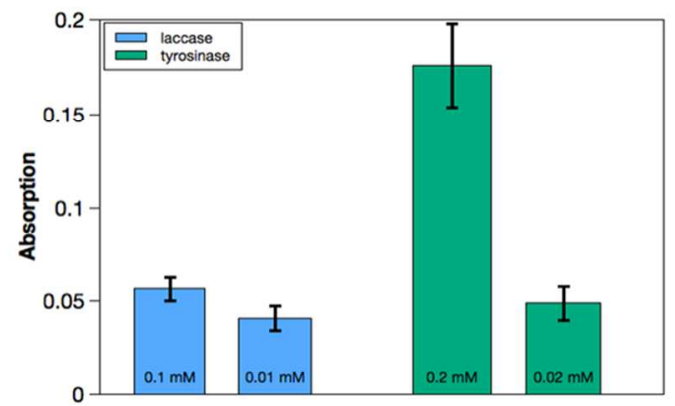

Figure 7. Activity of enzymes immobilized on the $\mathrm{A}_{45}-\mathrm{B}_{101}-\mathrm{C}_{27}$ block copolymer films as determined by oxidative product formation. (A) Laccase with $0.1 \mathrm{mM}$ DMP as substrate which forms a product with a characteristic UV/vis absorption $(\lambda=470)(\mathrm{A})$, and (B) tyrosinase with $0.2 \mathrm{mM} 4-\mathrm{MP}$ as substrate forming a product that can be detected by $U V /$ vis absorption at $\lambda=492$ ). Curves are based on: monolayer ( $m$, blue), up-down monolayer (ud, red), bilayer (uu, green), (lines added to guide the eye only). Activity of tyrosinase and laccase immobilized on the bilayer (uu) for two different concentrations of the enzyme substrates (C): DMP $0.1 \mathrm{mM}$ and $0.01 \mathrm{mM}$ (after $24 \mathrm{~h}$ ), and 4-MP $0.2 \mathrm{mM}$ and $0.02 \mathrm{mM}$ (after $3 \mathrm{~h}$ ). Enzymatic activity is shown via absorption intensity as measured and product concentration $(\mu \mathrm{M})$ as calculated using the calibration curves in Figure S6. For all measurements, background correction has been performed by subtraction of the absorption intensity obtained when the enzyme substrate was added to the polymer membrane.

Enzymes immobilized on an up-down monolayer resulted in a more active surface than the monolayer. Different parameters may account for these differences in behavior, it may be related 
to the different roughness of these films, which affects the accesibility of the enzymes. In addtion, different enzyme conformations resulting in reduced conformational freedom of the enzyme that are affecting the mode of interaction between the enzyme and substrate may also affect the enzyme activity on the polymeric membranes. Importantly, both laccase and tyrosinase remained active upon adsorption on the polymer films as indicated by the increase in absorption. Yet, compared to free enzyme in solution the adsorbed enzymes have lower activity, which might be related to various molecular factors, as for example to the reduced acessibility of adsorbed enzymes or reduced conformational freedom of the enzyme. The stability of the films has been evaluated by preparing them two weeks and one day before the enzyme immobilization, respectively. As the activity for both laccase and tyrosinase did not change, it indicates that the films preserve their properties up to two weeks (Figure S7, Supporting Information). The measured activity was compared with the activity that is theoretically expected if the enzyme is fully accesible to the substrates (Figure S8, Supporting Information). The theoretically expected and measured activity are very similar for tyrosinase immobilized on the bilayer polymer film (up-up). For laccase, however, the measured activity is clearly lower than what would be exptected based on the amount of immobilized enzyme. This behavior is indicating a reduced accessibility of the enzyme after imobilization. Importantly, a comparison with surfaces that are not functionalized with polymer membranes.further underlines the advantageous effect of the polymers as there is hardly any enzymatic activity observed on bare silica despite a higher amount of adsorbed enzyme.

Together, the stability of the solid supported copolymer films and the preserved bioactivity indicate that these active surfaces have high potential upon optimization, for phenol and phenol derivatives biosensing. 


\section{CONCLUSIONS}

The advantageous combination of the intrinsic bio-activity of the enzymes with the robustness and versatility of solid supported polymer membranes allows production of efficient "active surfaces". In this respect, a systematic analysis of the effects of the molecular factors of the polymer membranes on the activity of the enzymes represents a crucial step that is necessary to control the efficacy of such functional planar membranes and advance their development for production of desired compounds or for biosensing. We reported here polymer membranes that provide a stable, solid-supported environment for the enzymes. Interaction of both enzymes with different arrangements of the polymer films produced by LB transfer: mono- and bilayers with different morphology and properties (film thickness, wettability and roughness) were investigated. The three most promising polymer films (the monolayer, the up-down monolayer and the bilayer) were selected for enzyme adsorption and activity studies. It was observed that enzyme adsorption on the polymeric film is affected more by electrostatic interactions at enzyme/polymer interface than by surface roughness. Whilst both, laccase and tyrosinase preserved their enzymatic activity upon adsorption on the different types of polymer films, their activity was affected by the type of polymer film: bilayer films showed the highest activity for both enzymes. Therefore, bilayers are the most appealing candidates for combination with enzymes to sustain enzymatic reaction for sensing applications in aqueous environments. However, in order to advance towards potential applications of such functional planar bio-hybrid membranes further optimization is necessary to support scale-up as biosensors for detection of phenol and its harmful derivatives, well known as pollutants of drinking and natural water. 


\begin{abstract}
ASSOCIATED CONTENT
Supporting Information: Characterization of the polymer films; AFM; roughness of synthetic films; QCM-D frequency changes; Adsorption of enzymes on synthetic films; Activity of the free laccase and tyrosinase; Absorption curves for tyrosinase and laccase on bilayer; Calibration curves for enzymatic product; Activity of the enzymes on bilayer two weeks after preparation; Relative enzymatic activity.
\end{abstract}

\title{
AUTHOR INFORMATION \\ Corresponding Author \\ *CGP, E-mail: cornelia.palivan@unibas.ch \\ Author Contributions \\ $\$ C D$ and VM contributed equally to this work.
}

\begin{abstract}
ACKNOWLEDGMENT
Financial support was provided by the Swiss National Foundation (SNF), the National Centre of Competence Molecular System Engineering (NCCR MSE) and the University of Basel, and this is gratefully acknowledged. CD acknowledges the financial support from the Swiss National Science Foundation, International Short Visit (IZK0Z2_150884). We would like to thank Prof. Patrick Shahgaldian and Mina Moradi for access to the Langmuir-Blodgett instrument for additional experiments.
\end{abstract}




\section{REFERENCES}

1. Küchler, A.; Yoshimoto, M.; Luginbühl, S.; Mavelli, F.; Walde, P., Enzymatic reactions in confined environments. Nat. Nanotechnol. 2016, 11, 409.

2. Biju, V., Chemical modifications and bioconjugate reactions of nanomaterials for sensing, imaging, drug delivery and therapy. Chem. Soc. Rev. 2014, 43 (3), 744-764.

3. Gunkel-Grabole, G.; Sigg, S.; Lomora, M.; Lorcher, S.; Palivan, C. G.; Meier, W. P., Polymeric 3D nano-architectures for transport and delivery of therapeutically relevant biomacromolecules. Biomater. Sci. 2015, 3 (1), 25-40.

4. Palivan, C. G.; Goers, R.; Najer, A.; Zhang, X.; Car, A.; Meier, W., Bioinspired polymer vesicles and membranes for biological and medical applications. Chem. Soc. Rev. 2016, 45 (2), 377-411.

5. Garni, M.; Thamboo, S.; Schoenenberger, C.-A.; Palivan, C. G., Biopores/membrane proteins in synthetic polymer membranes. Biochim. Biophys. Acta, Biomembr. 2017, 1859 (4), 619-638.

6. Kowal, J.; Zhang, X.; Dinu, I. A.; Palivan, C. G.; Meier, W., Planar Biomimetic Membranes Based on Amphiphilic Block Copolymers. ACS Macro Lett. 2014, 3 (1), 59-63.

7. Hartmann, M.; Jung, D., Biocatalysis with enzymes immobilized on mesoporous hosts: the status quo and future trends. J. Mater. Chem. 2010, 20 (5), 844-857.

8. Draghici, C.; Kowal, J.; Darjan, A.; Meier, W.; Palivan, C. G., "Active Surfaces” Formed by Immobilization of Enzymes on Solid-Supported Polymer Membranes. Langmuir 2014, 30 (39), 11660-11669.

9. Welch, M. E.; Doublet, T.; Bernard, C.; Malliaras, G. G.; Ober, C. K., A glucose sensor via stable immobilization of the GOx enzyme on an organic transistor using a polymer brush. $J$. Polym. Sci., Part A: Polym. Chem. 2015, 53 (2), 372-377.

10. Lane, S. M.; Kuang, Z.; Yom, J.; Arifuzzaman, S.; Genzer, J.; Farmer, B.; Naik, R.; Vaia, R. A., Poly (2-hydroxyethyl methacrylate) for enzyme immobilization: impact on activity and stability of horseradish peroxidase. Biomacromolecules 2011, 12 (5), 1822-1830.

11. Kowal, J. Ł.; Kowal, J. K.; Wu, D.; Stahlberg, H.; Palivan, C. G.; Meier, W. P., Functional surface engineering by nucleotide-modulated potassium channel insertion into polymer membranes attached to solid supports. Biomaterials 2014, 35 (26), 7286-7294.

12. Zhang, X.; Fu, W.; Palivan, C. G.; Meier, W., Natural channel protein inserts and functions in a completely artificial, solid-supported bilayer membrane. Sci. rep. 2013, 3, 1-7.

13. Lomora, M.; Gunkel-Grabole, G.; Mantri, S.; Palivan, C. G., Bio-catalytic nanocompartments for in situ production of glucose-6-phosphate. Chem. Commun. 2017, 53 (73), 10148-10151.

14. Villegas, L. G. C.; Mashhadi, N.; Chen, M.; Mukherjee, D.; Taylor, K. E.; Biswas, N., A Short Review of Techniques for Phenol Removal from Wastewater. Curr. Pollut. Rep. 2016, 2 (3), 157-167.

15. Cabaj, J.; Sołoducho, J.; Chyla, A.; Bryjak, J.; Zynek, K., The characterization of ordered thin films built of immobilized phenoloxidases. Sens. Actuators, B 2009, 136 (2), 425-431.

16. Cabaj, J.; Sołoducho, J.; Nowakowska-Oleksy, A., Langmuir-Blodgett film based biosensor for estimation of phenol derivatives. Sens. Actuators, B 2010, 143 (2), 508-515.

17. Cabaj, J.; Sołoducho, J.; Świst, A., Active Langmuir-Schaefer films of tyrosinaseCharacteristic. Sens. Actuators, B 2010, 150 (2), 505-512. 
18. Böyükbayram, A. E.; Kıralp, S.; Toppare, L.; Yağc1, Y., Preparation of biosensors by immobilization of polyphenol oxidase in conducting copolymers and their use in determination of phenolic compounds in red wine. Bioelectrochemistry 2006, 69 (2), 164-171.

19. Ameer, Q.; Adeloju, S. B., Development of a potentiometric catechol biosensor by entrapment of tyrosinase within polypyrrole film. Sens. Actuators, B 2009, 140 (1), 5-11.

20. Matter, Y.; Enea, R.; Casse, O.; Lee, C. C.; Baryza, J.; Meier, W., Amphiphilic PEG-bPMCL-b-PDMAEMA Triblock Copolymers: From Synthesis to Physico-Chemistry of SelfAssembled Structures. Macromol. Chem. Phys. 2011, 212 (9), 937-949.

21. Vogt, B. D.; Lin, E. K.; Wu, W.-1.; White, C. C., Effect of Film Thickness on the Validity of the Sauerbrey Equation for Hydrated Polyelectrolyte Films. J. Phys. Chem. B 2004, 108 (34), 12685-12690.

22. Gunkel, G.; Huck, W. T. S., Cooperative Adsorption of Lipoprotein Phospholipids, Triglycerides, and Cholesteryl Esters Are a Key Factor in Nonspecific Adsorption from Blood Plasma to Antifouling Polymer Surfaces. J. Am. Chem. Soc. 2013, 135 (18), 7047-7052.

23. Qiu, H.; Xu, C.; Huang, X.; Ding, Y.; Qu, Y.; Gao, P., Immobilization of Laccase on Nanoporous Gold: Comparative Studies on the Immobilization Strategies and the Particle Size Effects. J. Phys. Chem. C 2009, 113 (6), 2521-2525.

24. Haefele, T.; Kita-Tokarczyk, K.; Meier, W., Phase Behavior of Mixed Langmuir Monolayers from Amphiphilic Block Copolymers and an Antimicrobial Peptide. Langmuir 2006, 22 (3), 1164-1172.

25. Vasquez, D.; Einfalt, T.; Meier, W.; Palivan, C. G., Asymmetric Triblock Copolymer Nanocarriers for Controlled Localization and pH-Sensitive Release of Proteins. Langmuir 2016, 32 (40), 10235-10243.

26. Kita-Tokarczyk, K.; Junginger, M.; Belegrinou, S.; Taubert, A., Amphiphilic Polymers at Interfaces. In Self Organized Nanostructures of Amphiphilic Block Copolymers II, Müller, A. H. E.; Borisov, O., Eds. Springer Berlin Heidelberg: Berlin, Heidelberg, 2011; pp 151-201.

27. Förch, R.; Schönherr, H.; Jenkins, A. T. A., Surface design: applications in bioscience and nanotechnology. John Wiley \& Sons: 2009.

28. Raposo, M.; Ferreira, Q.; Ribeiro, P., A guide for atomic force microscopy analysis of soft-condensed matter. Modern research and educational topics in microscopy 2007, 1, 758-769.

29. Girard-Egrot, A. P.; Godoy, S.; Blum, L. J., Enzyme association with lipidic LangmuirBlodgett films: Interests and applications in nanobioscience. Adv. Colloid Interface Sci. 2005, $116(1), 205-225$.

30. Piontek, K.; Antorini, M.; Choinowski, T., Crystal Structure of a Laccase from the FungusTrametes versicolor at 1.90- $\AA$ Resolution Containing a Full Complement of Coppers. $J$. Biol. Chem. 2002, 277 (40), 37663-37669.

31. Ismaya, W. T.; Rozeboom, H. J.; Weijn, A.; Mes, J. J.; Fusetti, F.; Wichers, H. J.; Dijkstra, B. W., Crystal Structure of Agaricus bisporus Mushroom Tyrosinase: Identity of the Tetramer Subunits and Interaction with Tropolone. Biochemistry 2011, 50 (24), 5477-5486.

32. Reviakine, I.; Johannsmann, D.; Richter, R. P., Hearing What You Cannot See and Visualizing What You Hear: Interpreting Quartz Crystal Microbalance Data from Solvated Interfaces. Anal. Chem. 2011, 83 (23), 8838-8848.

33. Mazur, M.; Krysiński, P.; Michota-Kamińska, A.; Bukowska, J.; Rogalski, J.; Blanchard, G. J., Immobilization of laccase on gold, silver and indium tin oxide by zirconium-phosphonatecarboxylate (ZPC) coordination chemistry. Bioelectrochemistry 2007, 71 (1), 15-22. 
34. Mahltig, B.; Gohy, J.-F.; Antoun, S.; Jérôme, R.; Stamm, M., Adsorption and structure formation of the weak polyelectrolytic diblock copolymer, PVP-b-PDMAEMA. Colloid Polym. Sci. 2002, 280 (6), 495-502.

35. Espín, J. C.; varon-castellanos, R.; Tudela, J.; Canovas, G., Kinetic study of the oxidation of 4-hydroxyanisole catalyzed by tyrosinase. 1997; Vol. 41, p 1265-76.

36. Kudanga, T.; Nemadziva, B.; Le Roes-Hill, M., Laccase catalysis for the synthesis of bioactive compounds. Appl. Microbiol. Biotechnol. 2017, 101 (1), 13-33. 


\section{$\underline{\text { TOC Graphic }}$}

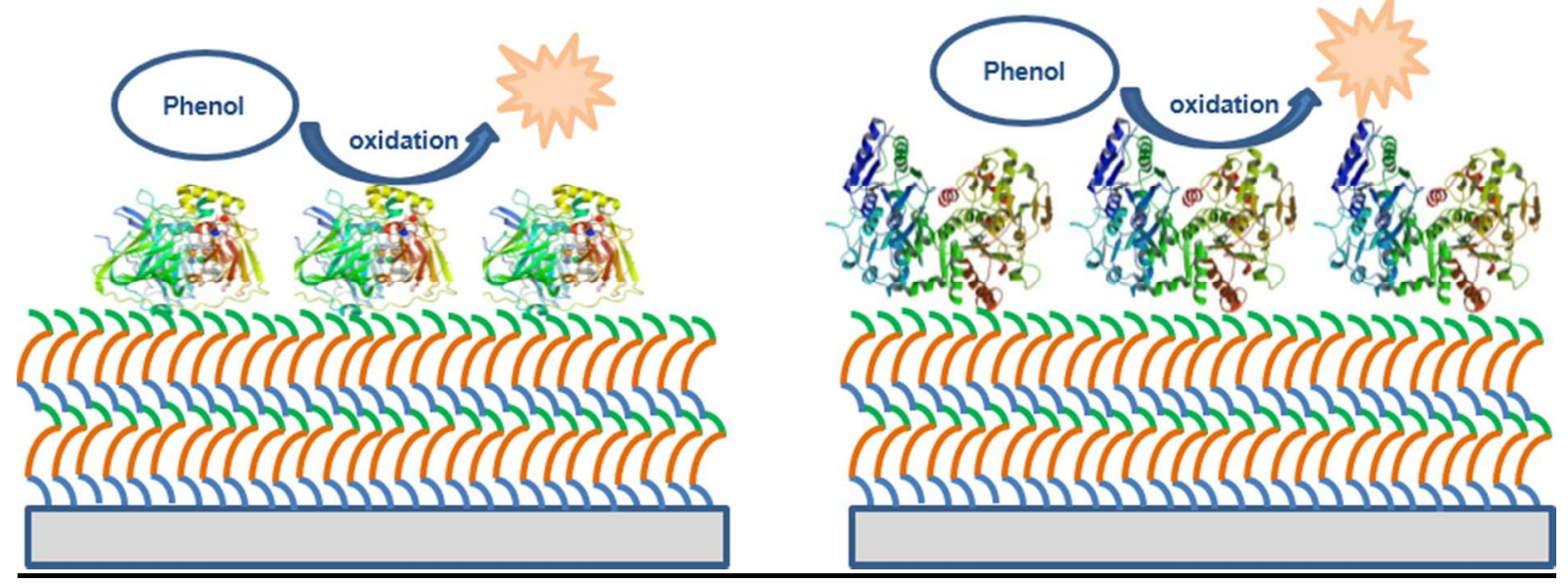

ACS Paragon Plus Environment 
Figure 1. PEG45-b-PMCL101-b-PDMAEMA27 copolymer used for solid supported membranes preparation. A to $D$ - principle of the Langmuir-Blodgett transfer technique: A - polymer spread at air-water interface; $B$ polymer film organization at air-water interface; C - polymer film compressed at air-water interface; D polymer transfer onto a hydrophilic solid support (a - up transfer, up lifting; b - down transfer, down dipping); E - BAM images with the polymer film organization at air-water interface (a - "mushroom"

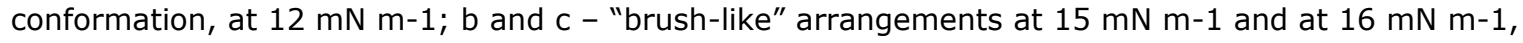
respectively; $\mathrm{d}$ - uniform film formed at collapse point, $26 \mathrm{mN} \mathrm{m-1).}$

$$
254 \times 338 \mathrm{~mm}(72 \times 72 \mathrm{DPI})
$$



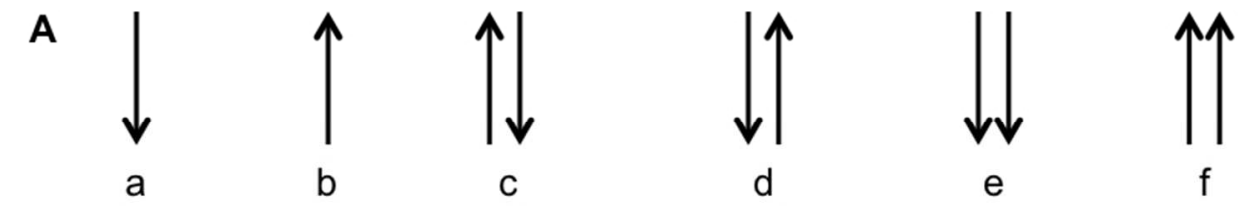

B

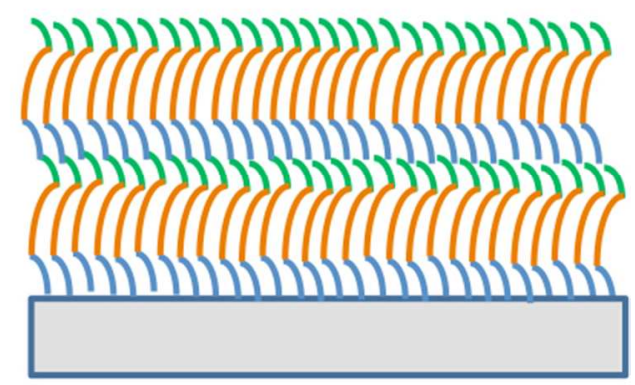

a

b

Figure 2. LB transfers to generate the polymer films: A - transfer directions (a - down transfer, down deeping; $b$ - up transfer, up lifting; c - up-down transfer; $d$ - down-up transfer; e - down-down transfer; $f$ - up-up transfer); $\mathrm{B}$ - films resulting from specific transfers ( $\mathrm{a}$ - monolayer film; b - bilayer film).

$224 \times 117 \mathrm{~mm}(96 \times 96 \mathrm{DPI})$ 
A

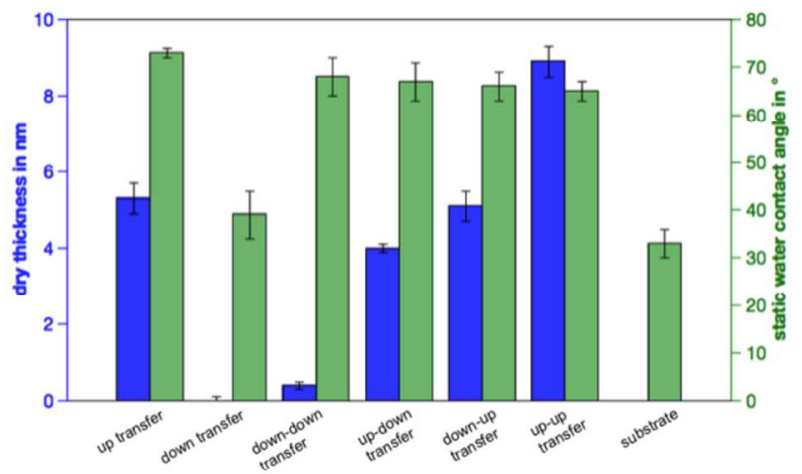

B
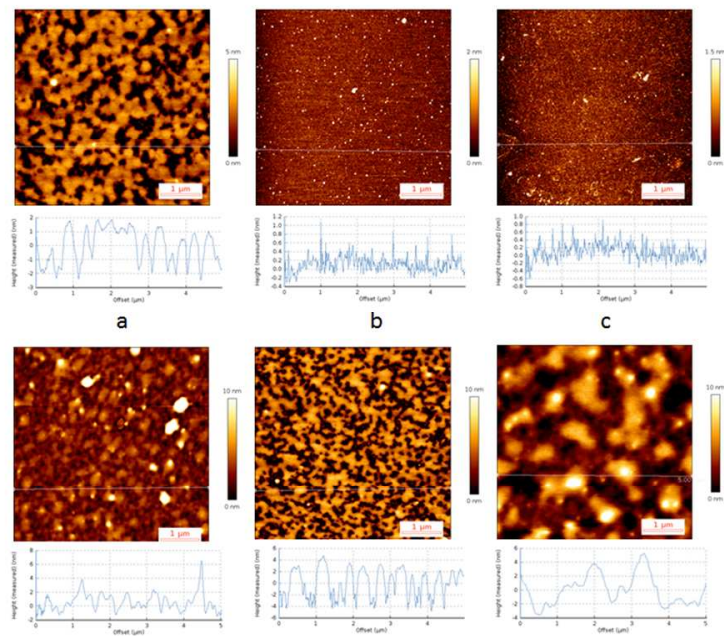

d

e

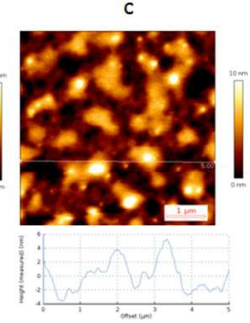

Figure 3. Characterization of different solid supported A45-B101-C27 copolymer films: A - thickness and wettability; B - AFM images (AC mode in air) with different transfer types and their height profiles (a - up transfer, monolayer film formed; b - down transfer, no film formation; c - down-down transfer, no film formation; d - down-up transfer, down-up monolayer film formed; e - up-down transfer, up-down monolayer film formed; $f$ - up-up transfer, bilayer film formed).

\section{$248 \times 398 \mathrm{~mm}(96 \times 96 \mathrm{DPI})$}



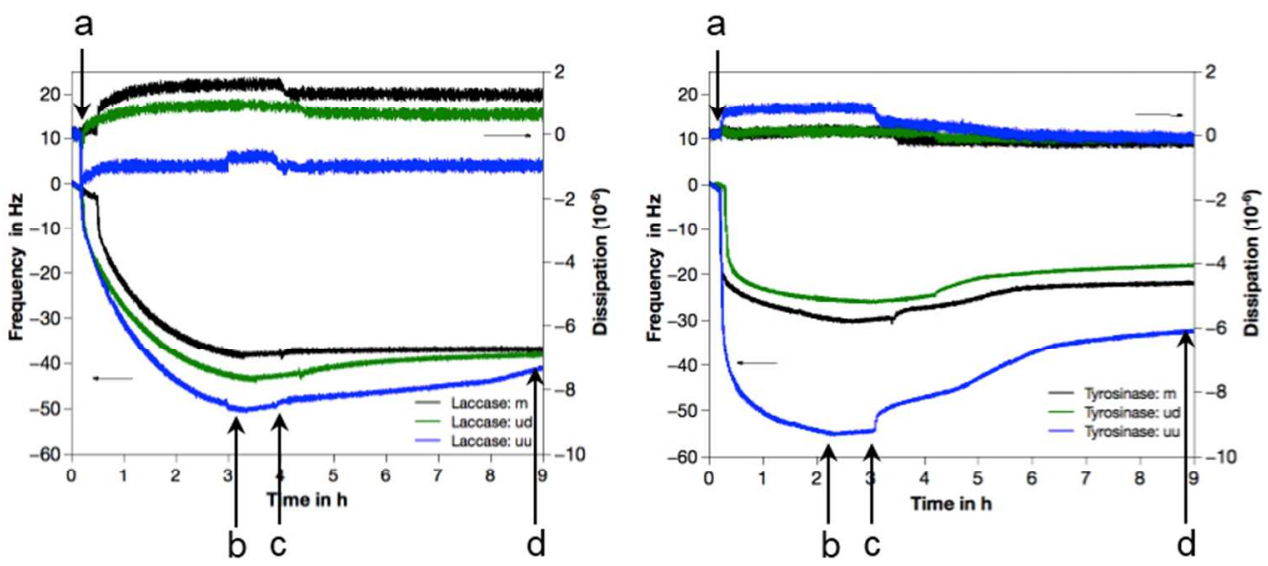

Figure 4. Changes in frequency (mass) and dissipation during the adsorption-incubation-desorption of laccase (left) and tyrosinase (right). Stages of enzymes adsorption: a - system stabilization (buffer flow); b - enzyme adsorption (enzyme flow); c - enzyme incubation (no flow); d - enzyme desorption (buffer flow). Both enzymes ( $0.5 \mu \mathrm{g} \mathrm{mL}-1)$ adsorbed on polymer membranes: monolayer $(\mathrm{m})$; up-down monolayer (ud) or bilayer (uu). QCM graphs were registered from the 5 th overtone.

$230 \times 107 \mathrm{~mm}(96 \times 96 \mathrm{DPI})$ 

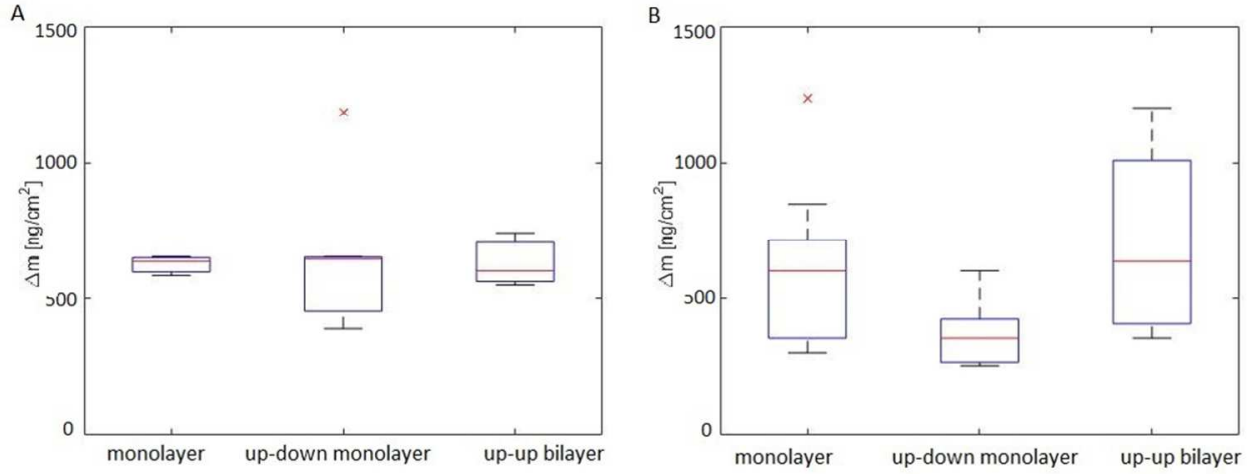

Figure 5. Amount of laccase (A) and tyrosinase (B) in $\mathrm{ng} / \mathrm{cm} 2$ calculated from QCM-D and shown in a boxplot with $n=3-6$.

$291 \times 111 \mathrm{~mm}(96 \times 96 \mathrm{DPI})$ 


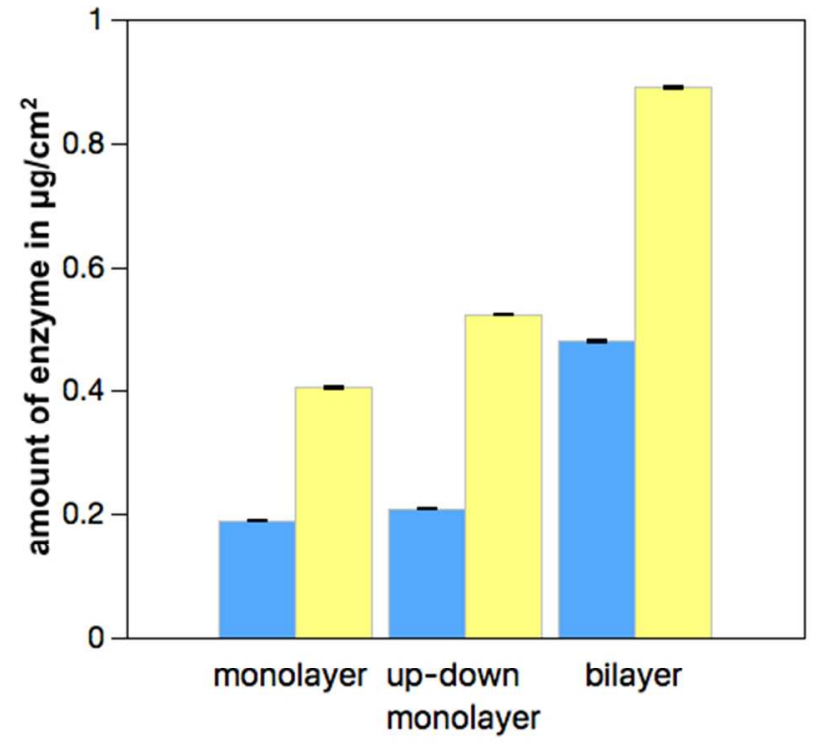

Figure 6. Amounts of laccase (blue) and tyrosinase (yellow) removed from the monolayer, up-down monolayer and bilayer polymer films, measured by BCA assay. The determined mass of the enzymes were expressed as mass per surface area $(\mu \mathrm{g} \mathrm{cm}-2)$.

$270 \times 179 \mathrm{~mm}(72 \times 72$ DPI $)$ 

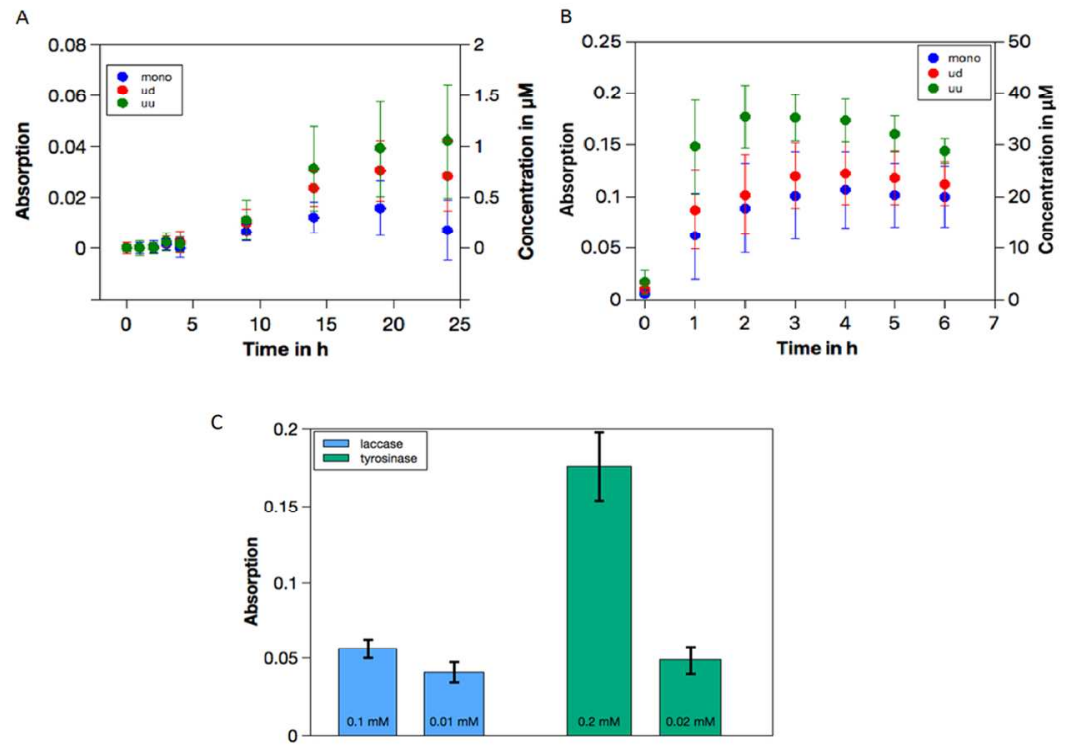

Figure 7. Activity of enzymes immobilized on the A45-B101-C27 block copolymer films as determined by oxidative product formation. (A) Laccase with $0.1 \mathrm{mM}$ DMP as substrate which forms a product with a characteristic UV/vis absorption $(\lambda=470)(A)$, and $(B)$ tyrosinase with $0.2 \mathrm{mM} 4-\mathrm{MP}$ as substrate forming a product that can be detected by UV/vis absorption at $\lambda=492)$. Curves are based on: monolayer ( $m$, blue), up-down monolayer (ud, red), bilayer (uu, green), (lines added to guide the eye only). Activity of tyrosinase and laccase immobilized on the bilayer (uu) for two different concentrations of the enzyme substrates (C): DMP $0.1 \mathrm{mM}$ and $0.01 \mathrm{mM}$ (after $24 \mathrm{~h}$ ), and 4-MP $0.2 \mathrm{mM}$ and $0.02 \mathrm{mM}$ (after $3 \mathrm{~h}$ ). Enzymatic activity is shown via absorption intensity as measured and product concentration $(\mu \mathrm{M})$ as calculated using the calibration curves in Figure S6. For all measurements, background correction has been performed by subtraction of the absorption intensity obtained when the enzyme substrate was added to the polymer membrane.

$262 \times 167 \mathrm{~mm}(150 \times 150 \mathrm{DPI})$ 


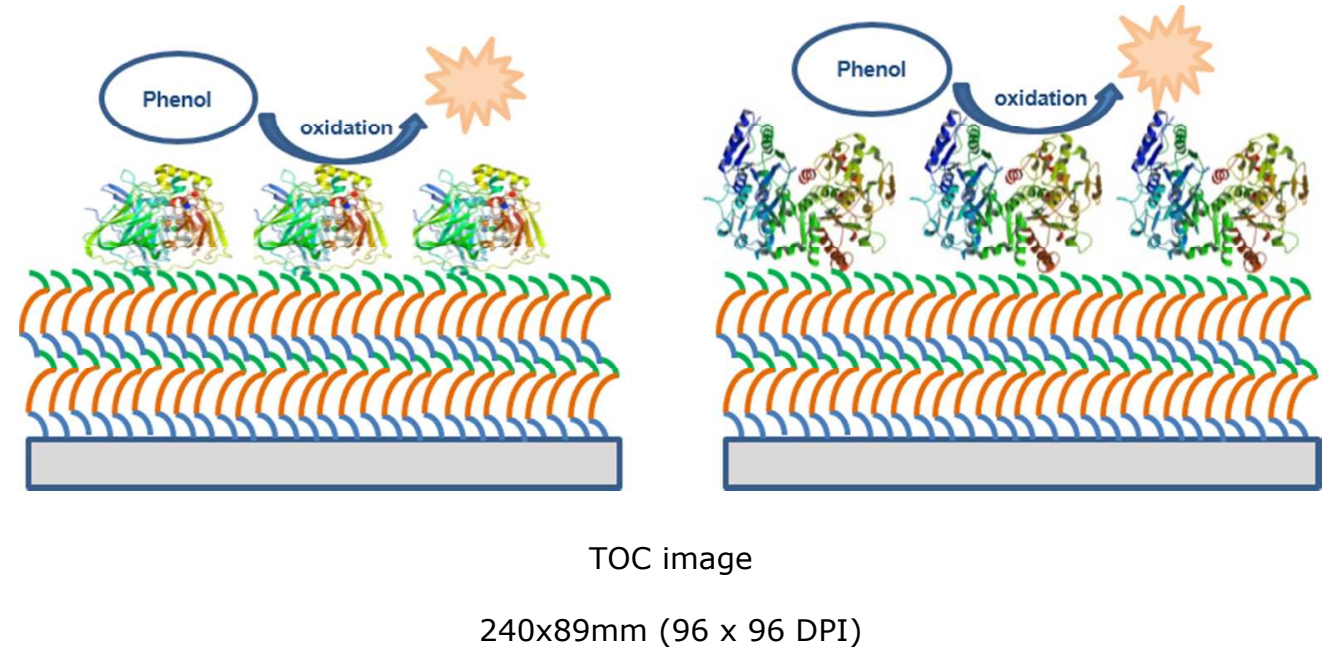

ACS Paragon Plus Environment 
A
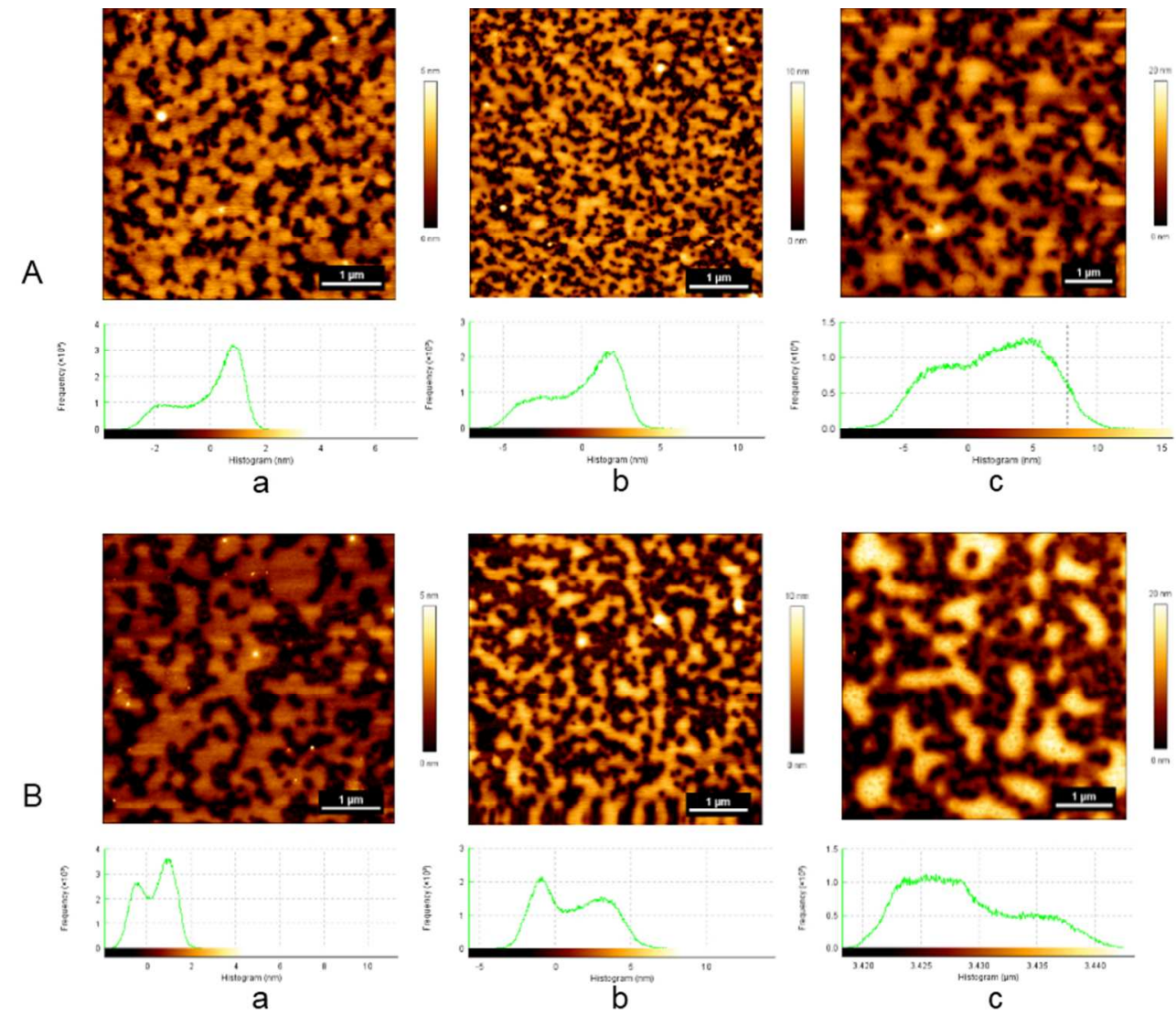

Figure S1. AFM images of the triblock copolymer film and the related histograms of the channel values: A after 1 week; B - after 3 months; a - monolayer film; b - up-down monolayer film; c - bilayer film.

$248 \times 214 \mathrm{~mm}(96 \times 96 \mathrm{DPI})$ 
A

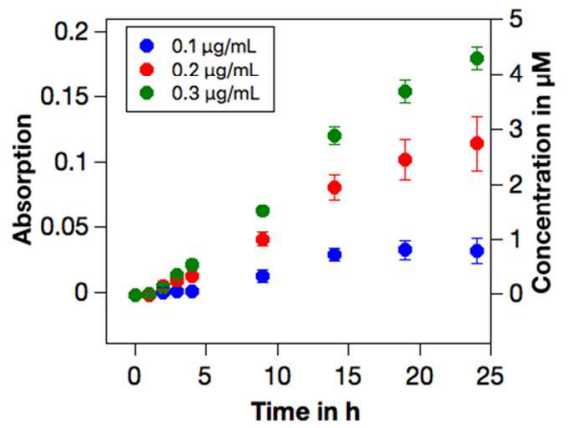

B

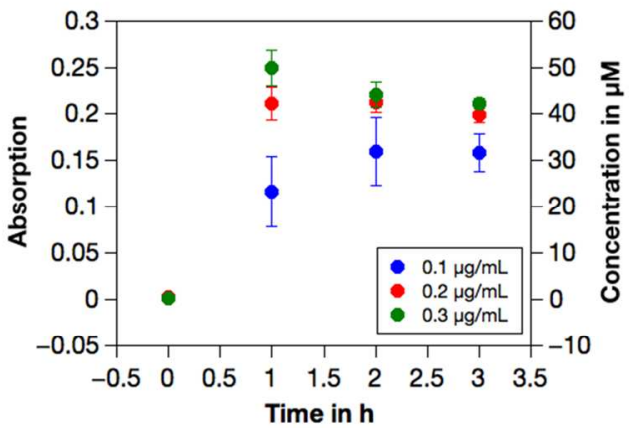

Caption : Figure S4. Activity of free (f) laccase (A) in the presence of DMP as substrate and tyrosinase (B) in the presence of 4-MP as substrate with different enzyme concentrations: $0.1 \mu \mathrm{g} \mathrm{mL}-1$ (blue), $0.2 \mu \mathrm{g} \mathrm{mL}-1$ (red), $0.3 \mu \mathrm{g} \mathrm{mL}-1$ (green). The activity is shown as absorption intensity (left) and as product concentration $(\mu \mathrm{M}$, right). The product concentration was calculated using the calibration curves shown in Figure S6

\section{7×169mm (96 x 96 DPI)}


A

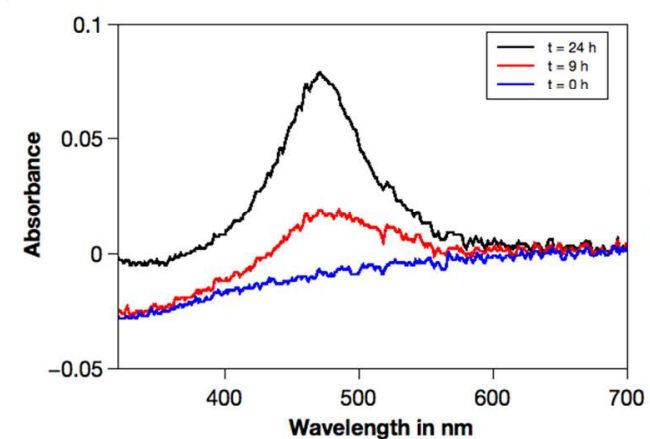

B

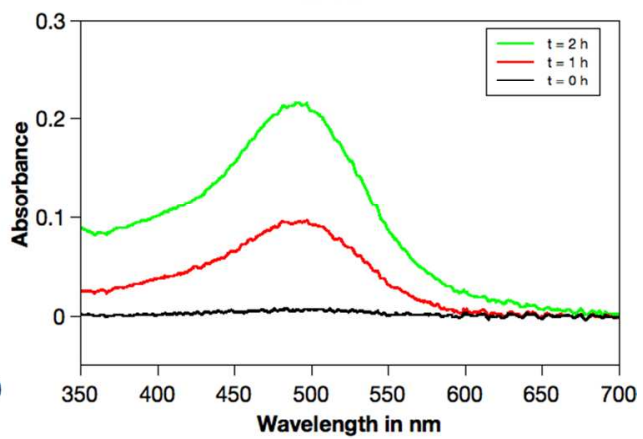

Figure S5. Absorption curves (raw data) of A) laccase with DMP (0.1 mM) and B) tyrosinase with 4-MP $(0.2$ $\mathrm{mM}$ ) on up-up bilayer showing the change in peak intensity over reaction time due to product formation.

$493 \times 186 \mathrm{~mm}(96 \times 96 \mathrm{DPI})$ 

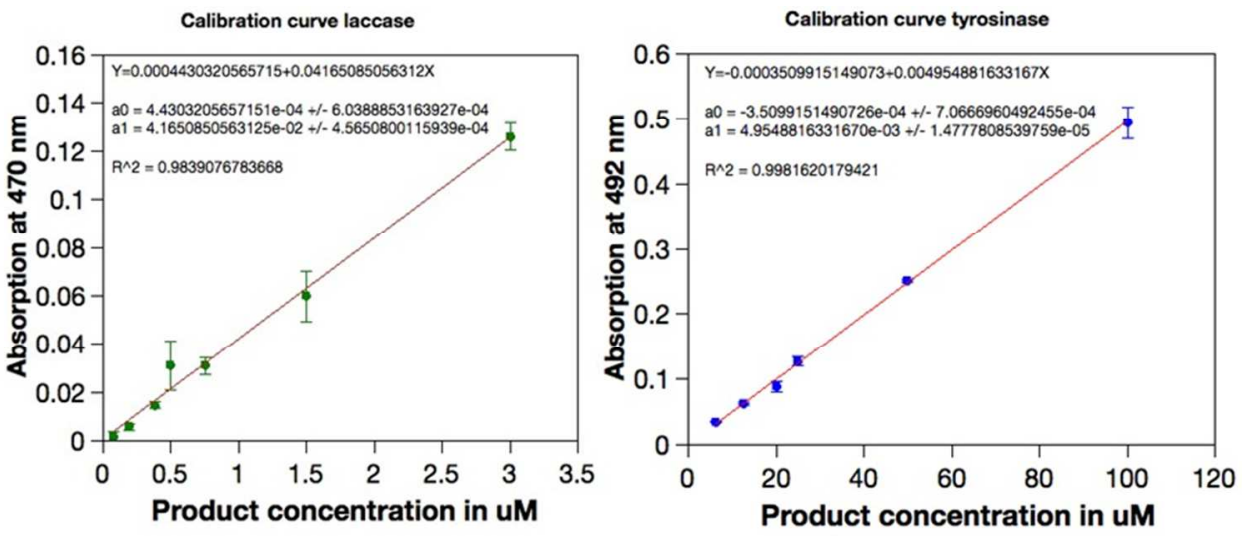

Figure S6. Calibration curves for enzymatic reactions. Left: Conversion of DMP by laccase , Right: Conversion of 4-MP and subsequent reaction with MBTH by Tyrosinase.

$$
159 \times 69 \mathrm{~mm}(150 \times 150 \mathrm{DPI})
$$




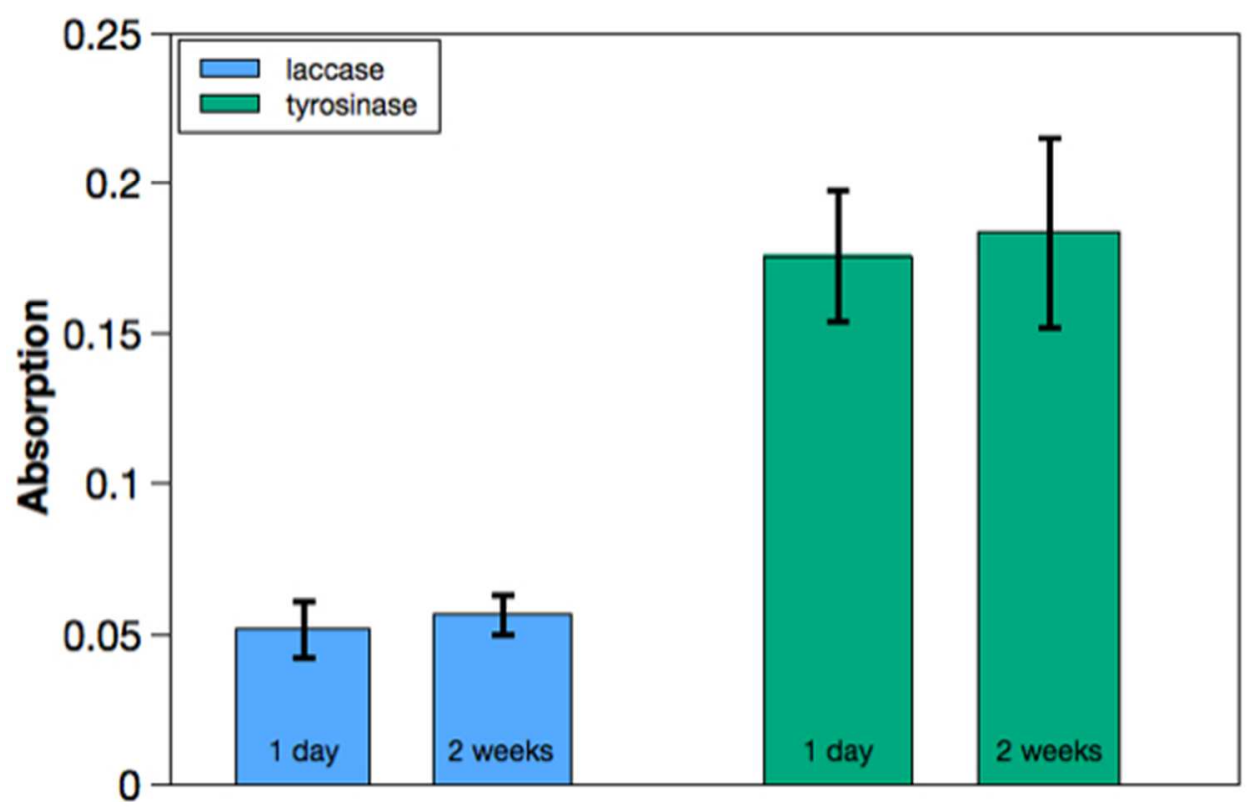

Figure S7. Activity of enzymes immobilized on the A45-B101-C27 block copolymer bilayer films with two weeks difference in preparation; laccase (blue) measured after $24 \mathrm{~h}$ with DMP as substrate $(0.1 \mathrm{mM}), \lambda \mathrm{max}$ $=470 \mathrm{~nm}$, tyrosinase (green) measured after $3 \mathrm{~h}$ with 4-MP as substrate $(0.2 \mathrm{mM}), \lambda \mathrm{max}=492 \mathrm{~nm}$; averages of four measurements were used; error bars give standard deviation. The dispersity of the values for the immobilized enzymes activity are due to several factors: polymer transfer on the silica support, enzyme adsorption onto the polymer film, type of enzyme and substrate.

$165 \times 125 \mathrm{~mm}(96 \times 96 \mathrm{DPI})$ 

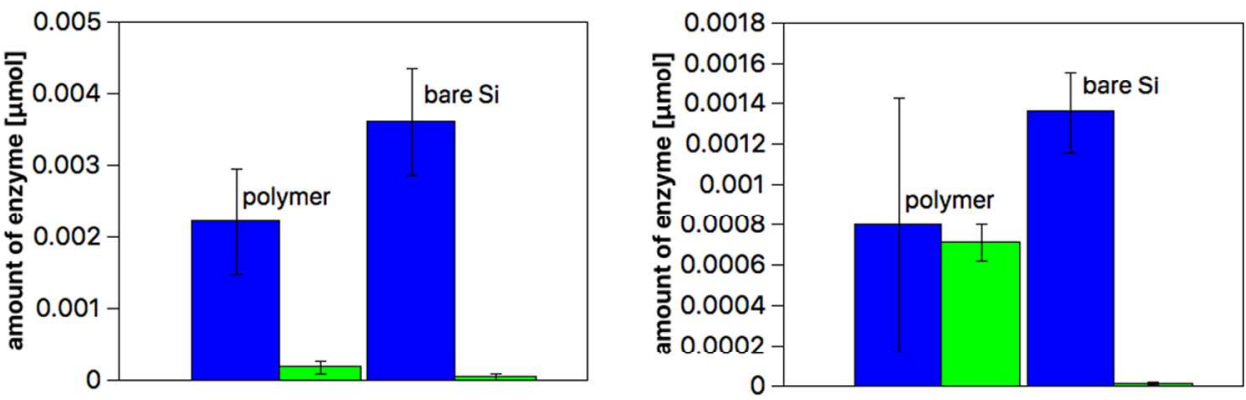

Figure S8. Determination of relative enzymatic activity of the enzymes laccase (left) and tyrosinase (right) on the bilayer polymer membrane (up-up) and on bare silicon wafer for comparison. The amount of enzyme on surface (blue) was calculated by subtracting the enzymatic activity determined in wash solutions from the washing solution used for immobilization. Hence, the reminder is assumed to be adsorbed on the surfaces. The result is compared to the experimentally determined result (green).

$$
341 \times 143 \mathrm{~mm} \text { (96 x } 96 \text { DPI) }
$$

